\title{
DIMENSIONES DE LA ADAPTACIÓN DE LAS VIVIENDAS PARA PERSONAS CON DISCAPACIDAD EN MÉXICO: TRES ESTUDIOS DE CASO
}

\section{DIMENSIONS OF HOUSING ADAPTATION FOR PEOPLE WITH DISABILITIES IN MEXICO: THREE CASE STUDIES}

\author{
NARVÁEZ TIJERINA, Adolfo \\ Universidad Autónoma de Nuevo León (UANL) \\ Facultad de Arquitectura (FARQ) \\ Profesor Titular C. Miembro del Sistema Nacional de Investigadores nivel III \\ Av. Universidad s/n cd. Universitaria C.P. 66451, San Nicolás de los Garza, Nuevo León, México \\ Teléfono: +52 (81) 83294160 Ext. 6790 \\ Correo electrónico: adolfo.narvaezti@uanl.edu.mx, adolfonarvaez@gmail.com
}

\section{FITCH OSUNA, Jesús Manuel}

Universidad Autónoma de Nuevo León (UANL)

Facultad de Arquitectura (FARQ)

Profesor Titular B. Miembro del Sistema Nacional de Investigadores nivel II

Av. Universidad s/n cd. Universitaria C.P. 66451, San Nicolás de los Garza, Nuevo León, México

Teléfono: +52 (81) 8329-4160 Ext. 6790 y 6704

Correo electrónico: jesus.fitchos@uanl.edu.mx, jesusfitch@hotmail.com

\section{VÁZQUEZ RODRÍGUEZ, Gerardo}

Universidad Autónoma de Nuevo León (UANL)

Facultad de Arquitectura (FARQ)

Profesor Titular A. Miembro del Sistema Nacional de Investigadores nivel II

Av. Universidad s/n cd. Universitaria C.P. 66451, San Nicolás de los Garza, Nuevo León, México

Teléfono: +52 (81) 83294160 Ext. 6790

Correo electrónico: gerardo.vazquezrd@uanl.edu.mx, gerardo7vazquez@gmail.com

Palabras clave: Personas con discapacidad; accesibilidad universal; arquitectura; vivienda

Key words: People with disabilities; universal accessibility; architecture; housing

\section{Resumen}

El trabajo trata sobre la adaptación de viviendas sociales para su uso por personas discapacitadas. La falta de una legislación mexicana que informe a los grandes constructores de vivienda social del país sobre normas de adaptación de viviendas para su uso por personas con discapacidad, ha generado un parque de viviendas pobremente adaptadas para su uso por parte de este segmento de población, que según cifras del INEGI ha alcanzado en 2010 los 5 millones 739 mil 270 personas, representando el $5.1 \%$ de la población total.

La perspectiva de adaptar las viviendas sociales construidas en México parece una labor imposible, a menos que se haga de manera tal que se busque adaptar ese parque caso por caso desde la perspectiva de trabajo cliente- arquitecto. El cálculo de los costes de tal adaptación es difícil de llevar a cabo, de manera que un cambio legislativo como el que es necesario llevar a cabo en México, se enfrenta al problema del financiamiento. Emprendimos un estudio de campo para empezar a medir el "tamaño" que alcanzaría una financiación encaminada a dotar de espacios accesibles a esta población. Analizamos tres modelos de vivienda social en Monterrey, destinados a tres segmentos de la población adquiriente de vivienda, desarrollados por dos de las empresas más importantes en el ramo en México. 
Se realizó un análisis arquitectónico detallado para calificar los problemas que presentan esos modelos de vivienda. Luego se realizaron proyectos de adaptación que tuvieran como mira el realizarlos buscando el menor costo de adaptación posible, inclusive utilizando la tecnología de punta en accesibilidad de personas discapacitadas, como recurso, de modo tal que nos permitiera prospectar el monto de inversión necesario para que una vivienda pasara a ser universalmente accesible.

\section{Abstract}

The work deals about the adaptation of social housing for use by disabled people. The lack of Mexican legislation that informs the large social housing builders of the country on housing adaptation standards for use by people with disabilities, has generated a housing stock poorly adapted to be used by this segment of the population, according to INEGI figures, in 2010 it reached 5 million 739 thousand 270 people, representing $5.1 \%$ of the total population.

The perspective of adapting social housing built in Mexico seems an impossible task, unless it is done in a way that seeks to adapt that park case by case from the client-architect job perspective. The calculation of the costs of such adaptation is difficult to carry out, so that a legislative change like the one that is necessary to carry out in Mexico, faces the problem of financing. We undertook a field study to begin measuring the "size" that would reach a funding aimed at providing accessible spaces to this population. We analyse three models of social housing in Monterrey, intended for three segments of the population that acquire housing, developed by two of the most important companies in the field in Mexico.

Adaptation projects were then carried out with the aim of realizing them looking for the lowest possible cost of adaptation, including using state-of-the-art accessibility technology for disabled people, as a resource, in such a way as to allow us to prospect the amount of investment necessary for a housing will become universally accessible.

\section{Introducción}

Este trabajo trata sobre la necesaria adaptación de viviendas sociales y los conjuntos urbanos en que éstas son desarrolladas para su uso por personas discapacitadas; de cómo el diseño en la mayor parte de los casos tiene que ser adaptado para que pueda ser usado y servir a personas con discapacidad, en la actualidad. La falta de una legislación mexicana que informe a los grandes constructores de vivienda social del país sobre normas de adaptación de viviendas para su uso por personas con discapacidad, ha generado un parque de viviendas pobremente adaptadas para su uso por parte de este segmento de población, que según cifras del INEGI ha alcanzado en 2010 los 5 millones 739 mil 270, personas, lo que representaba el $5.1 \%$ de la población total en ese año. La perspectiva de adaptar las viviendas sociales construidas en México parece una labor imposible, a menos que se haga de manera tal que se busque adaptar ese parque caso por caso desde la perspectiva de trabajo cliente-arquitecto.

Este trabajo, además de interesarse sobre lo que puede llegar a significar el lograr viviendas perfectamente adaptadas para su uso por personas con discapacidad y sus familias, se cuestiona sobre las razones por las que el diseño arquitectónico y urbano en la actualidad no se adapta para que las puedan usar estas personas. El vacío legislativo puede explicar una mínima parte de este problema, pues es quizás la manifestación de un problema social latente que tiene que ver con las maneras en que incorporamos a nuestras subjetividades a los

Citación: NARVÁEZ TIJERINA, A. et al. Dimensiones de la adaptación de las viviendas para personas con discapacidad en México: tres estudios de caso. En: Libro de proceedings, CTV 2018. XII Congreso Internacional Ciudad y Territorio Virtual. "Ciudades y Territorios Inteligentes". UNCuyo, Mendoza, 5-7 septiembre 2018. Barcelona: CPSV, 2018, p. 193-226. 
colectivos que salen del estereotipo del habitante urbano que hemos construido colectivamente y que se ha transformado en un símbolo con el apoyo de un gran aparato de comunicación y propaganda a través del que vemos a la realidad que nos rodea.

Uno de los asuntos que también toca este trabajo tiene que ver con el cálculo de los costes de la adaptación de las viviendas sociales para su uso por personas con discapacidad, de manera que un cambio legislativo como el que es necesario llevar a cabo en México, se enfrenta además de con las maneras en que pensamos a nuestras ciudades, con el problema del financiamiento. Como parte de esta labor, emprendimos un estudio de campo para empezar a medir el "tamaño" que alcanzaría una financiación encaminada a dotar de espacios totalmente accesibles a esta población.

Para ello, analizamos tres modelos de vivienda social en Monterrey, destinados a tres segmentos de la población adquiriente de vivienda, desarrollados por dos de las empresas más importantes en el ramo en México. Se realizó un análisis arquitectónico detallado para calificar los problemas que presentan esos modelos de vivienda. Luego se realizaron proyectos de adaptación que tuvieran como mira el realizarlos buscando el menor costo de adaptación posible, inclusive, utilizando la tecnología de punta en accesibilidad de personas discapacitadas, como recurso, de modo tal que nos permitiera prospectar el monto de inversión necesario para que una vivienda pasara a ser universalmente accesible. En cuanto concluimos esta primera aproximación, emprendimos una segunda experimentación a través del diseño, ahora con otras premisas, que nos permitieran contar con criterios más claros para dimensionar más objetivamente lo que es necesario hacer de cara a lograr una buena adaptación de la vivienda y su entorno para ser habitadas por personas con discapacidad.

Partimos de una clasificación de la población discapacitada por el tipo de discapacidad que presentan y el porcentaje de población que representan, elaborando una clasificación de los problemas de adaptación que presentan las viviendas objeto del estudio, para detallar la prospección financiera, de manera de que este estudio pudiera servir tanto a constructores de nuevas viviendas, como a los legisladores en su trabajo.

El estudio permite ver desde tres estudios de caso, el estado actual de la adaptación de la vivienda social en México para personas con discapacidad. Se elaboran en la parte final del trabajo, algunas reflexiones sobre el diseño urbano actual de conjuntos habitacionales sociales en México y la necesidad de modificar parámetros de diseño con el fin de construir entornos socialmente incluyentes y universalmente accesibles. Se presenta la discusión sobre qué parámetros habrían de ser modificados y de qué maneras.

\subsection{El habitante urbano: la exclusión y la construcción de un imaginario hegemónico}

¿Quién es el habitante urbano hoy? Quizás para definir al habitante urbano de hoy, necesitaríamos adoptar una visión abierta y que trabajara merced a la analogía. También deberíamos en esta discusión partir de la noción de que "el habitante urbano" es en sí una categoría semántica que se sostiene en una entelequia tendida entre las imágenes que en un número enormemente creciente inundan nuestro día a día y con las que se nutre nuestra subjetividad. Así, cabe plantear como principio para la búsqueda de los significados, que la noción en sí del habitante urbano es una construcción hipotética que con el apoyo de las imágenes en circulación, ha tomado visos de verdad inconmovible.

Citación: NARVÁEZ TIJERINA, A. et al. Dimensiones de la adaptación de las viviendas para personas con discapacidad en México: tres estudios de caso. En: Libro de proceedings, CTV 2018. XII Congreso Internacional Ciudad y Territorio Virtual. "Ciudades y Territorios Inteligentes". UNCuyo, Mendoza, 5-7 septiembre 2018. Barcelona: CPSV, 2018, p. 193-226. 
Un anuncio en cualquier carretera de las que rodean a la periferia de Monterrey, y que puede también ilustrar la periferia de otras ciudades mexicanas, es la de lo que a simple vista nos puede parecer una familia (un hombre y una mujer jóvenes acompañados por dos niños de unos 6 a 10 años de edad). El hombre carga en hombros al niño, reflejando el gusto de tener un tiempo para jugar con él, lo rodean a su lado izquierdo la mujer, joven y atractiva, pero que por su actitud y ropa parece más que una exótica modelo de pasarela, una madre de familia guapa, y del otro lado una niña pequeña, sonriente.

El hombre en estos anuncios de las periferias carga en sus hombros la responsabilidad de todo ese núcleo que se arracima a su alrededor como reclamando protección, bienestar y cobijo. La imagen de la mujer, de la jefa de familia en estos anuncios, cede su poder al macho, para mostrarse sometida, a la espera de recibir del poder del varón un bienestar que llevará a ella y a sus críos a vivir en un paraíso patriarcal, sereno, verde y de solaz. Vivir en un patrimonio. Estableciendo así las bases de una riqueza afincada en la casa, centro de los afanes y así de todas las imágenes de la seguridad y la paz.

Son abundantes en estos anuncios las imágenes de centros de colonia arbolados, que ofrecen equipamientos que puedan hacer realidad la imagen del juego cotidiano del patriarca y su familia. Una alberca común, canchas juegos infantiles o espacios para jugar, para tenderse en el idílico día de campo. El verde parece dominar por entre otros colores en estas imágenes que así remiten a un campo soñado, a la naturaleza, para de este modo ir negando subrepticiamente a lo urbano.

Como en un sueño, que remite frontalmente a una de las utopías formadoras del imaginario de Occidente, la familia ideal se dirige a su retiro cotidiano en los campos, lejos de la ciudad asfixiante. La imagen que usan estas empresas desarrolladoras de viviendas, tiene que ver con la huida a una realidad que está al margen de la ciudad, en medio de un espacio verde que se concibe como "el campo", a sabiendas de que en efecto se trata de una periferia conquistada, de un lugar domesticado. En algunas ocasiones, es hasta un cierto punto contradictorio encontrar esos carteles de propaganda justamente al lado de fábricas, donde se han encontrado terrenos libres para edificar esos desarrollos que remiten a esa vida soñada.

El habitante urbano que es promovido a través de esos recursos de la propaganda se intuye como conformando un perfil muy bien definido: Como perteneciente a una familia nuclear pequeña; compuesta por jóvenes, con jefatura masculina, el patriarca y la madre se conciben como gente fuerte, con recursos que les permiten estar saludables y bien alimentados, que poseen automóvil (cada uno de los padres) y que pueden desarrollar la práctica de algun deporte. En todo caso, remiten a la necesaria imagen de un trabajador asalariado.

Las imágenes a través de las que las empresas desarrolladoras venden estas casas implican el haber optado por una población objetivo que al estar así delimitada excluye a otras personas que se encuentren bastante lejos de ese ideal: hogares monoparentales, jefatura femenina, familias extensas, ancianos en la transición posterior a la crianza de sus hijos, adultos jóvenes viviendo solos, ancianos solos, familias con personas con discapacidad, personas discapacitadas viviendo solas, desempleados, personas que no poseen automóviles, grupos indígenas, otras minorías, etc.

A través de este trabajo veremos que esta delimitación que es visible a través de las imágenes de venta, puede estar relacionada con unas decisiones de diseño instrumentadas por unas políticas empresariales basadas en lograr la maximización de las ganancias del capital invertido, pero a costa de generar productos que solamente resultan útiles para segmentos muy específicos de la población.

Citación: NARVÁEZ TIJERINA, A. et al. Dimensiones de la adaptación de las viviendas para personas con discapacidad en México: tres estudios de caso. En: Libro de proceedings, CTV 2018. XII Congreso Internacional Ciudad y Territorio Virtual. "Ciudades y Territorios Inteligentes". UNCuyo, Mendoza, 5-7 septiembre 2018. Barcelona: CPSV, 2018, p. 193-226. 
El asunto es en sí grave, ya que no se trata del producto que ofrece una empresa privada para la venta en un mercado abierto, sino del concurso de empresas que emplean recursos públicos que están dirigidos a paliar una necesidad social clave, como lo es la vivienda. La dirección de las políticas públicas, que deberían reclamar por la inclusión justa y equitativa de todos los habitantes en cada condición particular en que estos estén, debería en este caso encaminarse a lograr modelos de vivienda que fueran útiles para todos, no solamente para un grupo restringido de usuarios. Esto es importante apuntarlo, pues el ejercicio de los recursos públicos no debería estar encaminado únicamente a la maximización de los rendimientos del capital, sino mayormente a lograr que las políticas públicas sean instrumentadas en forma adecuada, equitativa, democrática e incluyente.

El que en este momento en el país esto no se lleve a cabo de una manera óptima puede estar relacionado entre otras razones ${ }^{1}$ con un vacío institucional: que las normativas dedicadas a velar porque la vivienda se construya con calidad suficiente, es incompleta cuando se trata de temas de inclusión y acceso universal; que las políticas públicas en la materia no promueven abierta y frontalmente la inclusión y acceso universal; que los organismos encargados de instrumentar las políticas y velar por la aplicación de las normativas se han desentendido de su labor o no cuentan con recursos e instrumentos suficientes para llevarla a cabo; que no existen instancias de vigilancia y escrutinio de lo que las empresas desarrolladoras y financiadoras de la vivienda hacen con recursos públicos; que las empresas desarrolladoras y financiadoras de la vivienda estén únicamente interesados por la maximización del rendimiento del capital y no tengan una seria, comprometida y verdadera solidaridad social.

Si estas situaciones abiertamente injustas se aceptan así sin más puede estar relacionado con un hecho subjetivo: hemos aceptado el imaginario social al que señalan esas imágenes publicitarias que apoyan la visión única de la idílica "familia perfecta". Con lo que nosotros mismos, subrepticiamente, hemos contribuido a sostener una manera de concebir a la vivienda que directamente mana de una hegemonía que excluye. El cambiar este estado de cosas es un asunto entonces que se vuelve parte del despertar crítico de nosotros, de que construyamos los instrumentos e instituciones para lograr la justicia, equidad, inclusión y tolerancia, que indiquemos claramente al gobierno y a las empresas que lo que esperamos -como ciudadanía y como consumidores- es que gobierno, empresas y sociedad se funden sólidamente sobre las bases de una verdadera solidaridad social.

\subsection{La discapacidad, las normativas de diseño y las construcciones, panorama actual}

A través de los expuesto se comprende que la manera de diseñar y construir las viviendas en México por parte de los grandes desarrolladores inmobiliarios, resultan estar muy mal adaptadas para su uso por las personas y los colectivos que no "encajen" en el molde ideal del ciudadano objetivo de esos diseños. Las personas con discapacidad en el país, resultan ser de los colectivos más vulnerables ante estas faltas de ajuste, pues sus requerimientos en muchos de los casos son muy distantes de los proyectados para las viviendas sociales.

\footnotetext{
1 Una de estas otras razones tendría que ver con la propia historia reciente de la arquitectura e ingeniería, que afincada en los ideales del Movimiento Moderno de principios del siglo XX, establecería métodos de trabajo basados fundamentalmente en la idealización de unos seres humanos, cuyas medidas serían usadas para establecer las dimensiones mínimas de diseños estandarizables. Se puede relacionar la actual falta de ajuste de los diseños con los requerimientos de personas y colectivos muy diferentes de esos tipos ideales, justamente con el uso de esos ya obsoletos métodos de diseño, por gran parte de los profesionales encargados de los diseños y construcciones de viviendas en México. 
Tras del escenario de las declaraciones públicas suelen esgrimirse como razones de ello dos argumentaciones: que las personas con discapacidad actual no llegan a ser una masa lo suficientemente grande como para que resulte rentable hacer diseños especiales para ellos y que los costos de producción de una vivienda perfectamente adaptada sobrepasarían las capacidades económicas de la población adquiriente de créditos, por lo que de plano construir así no sería negocio.

En repetidos ámbitos profesionales y de gobierno con los que he tenido contacto por esta investigación, he escuchado estas argumentaciones por parte de profesionistas de la construcción y funcionarios. $Y$ aunque nunca lo reconocerán en público (siempre que me han dicho tales cosas me advierten que eso debe de quedar fuera de mis registros), estas razones ocultas parecen guiar la mayoría de sus decisiones.

De cara a este panorama es necesario hacer investigaciones que aclaren sobre cuál es la situación de la población con discapacidad, así como el llevar a cabo análisis detallados de las viviendas en el mercado, con el fin de hacer una evaluación objetiva de los costos de los diseños hechos para estar adaptados completamente para su uso por este colectivo.

¿Quiénes son las personas con discapacidad en México? Una consideración radical sobre el problema supondría pensar en que potencialmente todas las personas podrían en un momento dado de su vida, ya sea por accidente, por problemas hereditarios o de nacimiento o por enfermedad, ser discapacitados. No obstante que esta posición es absolutamente lógica, puede no ser una buena guía para tomar decisiones sensatas en política pública y en economía. Las estadísticas nacionales, por otra parte, pueden ayudarnos a observar tendencias y patrones en la evolución de este colectivo.

De acuerdo a la información del censo de 2010, actualmente en el país existe una población de personas con discapacidad que rebasa ya los 5 millones 739 mil 270 habitantes, lo que representa más del $5.1 \%$ de la población de la nación. Poniendo esto en perspectiva y asumiendo que los costos de la discapacidad reposan en la mayor parte de los casos en la familia de la persona con discapacidad, esta cifra puede extenderse hasta unas; 17 millones 660 mil personas, lo que ya representa cerca del $15.7 \%$ de la población de todo el país.

Es necesario que se desarrollen esquemas de integración de este colectivo al resto de la sociedad mexicana, toda vez que es importante preservar el espíritu de inclusión y pleno derecho de todos los ciudadanos que formamos parte de un país que como uno de sus más valiosos fundamentos tiene a la democracia.

México es signatario desde el año 2006 de la Convención sobre los Derechos de las Personas con Discapacidad, que establece directrices claras que pueden ser interpretadas y aplicadas al diseño de lugares más adecuados, adaptados y accesibles para las personas con discapacidad, incluidos aquellos en que se desarrolla su vida privada (Quinn y Degener, 2002). Para el año 2007, el Senado de la República haría suyo el espíritu de esa convención, abocándose a emitir las leyes necesarias para hacer valer los derechos universales de las personas con discapacidad.

Con base al uso de normas y criterios nacionales previos, este mandato internacional, sostiene fundamentos para el diseño de políticas con estos fines que pueden llegar a tener un impacto claro en el diseño de los lugares y de los edificios. Sin embargo, las revisiones internacionales recientes en esta materia, no alcanzan a cubrir las áreas de intervención de la convención. Por ejemplo, la Architectural and Transportation Barriers Compliance Board del gobierno federal estadounidense (Wakefield, 2000), no concibe su aplicación más allá de la esfera de los usos

Citación: NARVÁEZ TIJERINA, A. et al. Dimensiones de la adaptación de las viviendas para personas con discapacidad en México: tres estudios de caso. En: Libro de proceedings, CTV 2018. XII Congreso Internacional Ciudad y Territorio Virtual. "Ciudades y Territorios Inteligentes". UNCuyo, Mendoza, 5-7 septiembre 2018. Barcelona: CPSV, 2018, p. $193-226$. 
públicos y comerciales de las directrices de la convención. Adaptaciones a los ámbitos de la vivienda y espacios privados no son concebidas dentro de este mandato.

Similarmente, en la normativa mexicana derivada de las diversas legislaciones que abordan los derechos de las personas discapacitadas y su relación con los espacios arquitectónicos y urbanos, (por ejemplo, en las normativas de construcciones de los estados) estos ámbitos quedan fuera de la aplicación de la normativa, concentrándose en regular la eliminación de obstáculos para el tránsito en los espacios públicos, similarmente a lo que establece la normativa estadounidense referida.

En la normativa específica para el sector salud, que es de las más desarrolladas y robustas en México (NOM-233-SSA1-2003), sólo se reconoce la parte del problema relacionada con la movilidad física, quedando sin atención otros aspectos del diseño arquitectónico y urbano que impactan al objetivo de lograr equidad, inclusión y participación de las personas con discapacidad en todos los ámbitos de la vida en nuestra sociedad.

Cabe señalar otro problema que se suma al anterior, y es el de que a pesar de que existe un robusto marco normativo en la materia (aunque con la necesidad manifiesta de su perfeccionamiento), la aplicación universal de ésta dista mucho de poder ser llevada a cabo, atribuible en gran medida a la falta de control, vigilancia o deficiencias en la gestión pública.

A pesar de que las áreas de interés de las normativas urbanísticas y para el diseño arquitectónico abarcan aspectos importantes para la eliminación de barreras para las personas con discapacidad, la total inclusión de éstas dista mucho de ser totalmente adecuada. Tanto en aspectos de planeación de densidades, en el uso de materiales, en el diseño con respecto al clima (considerando evidentemente tiempos diferenciados de recorrido al exterior, por ejemplo), en cuestiones dimensionales, en la adopción de tecnologías, como en aspectos que cuiden la identificación y la efectiva apropiación de los espacios urbanos por parte de las personas con discapacidades, son importantes ausentes de las normativas en uso.

Ni qué decir del diseño de las viviendas, que difícilmente se puede adaptar al tránsito interior ni a la permanencia por largos periodos (dada su falta de adaptación a los cambios climáticos, frío o calor extremos que tienen que soportar las personas discapacitadas) ni en cuanto a un diseño que permita desarrollar con plenitud el bienestar psicológico de esta población. Una intervención en este sector de la construcción, implicaría no sólo cambios en las superficies útiles de la propia vivienda, sino adaptaciones de materiales, alturas de elementos útiles (ventanas, cerraduras, aparatos sanitarios, cocinas, etc.), hasta cambios sustanciales en el diseño interior, con un evidente impacto en el diseño de los espacios exteriores.

Si a lo anterior sumamos el hecho de que la falta de variedad urbana (Bentley et al., 1999) que caracteriza a los nuevos conjuntos habitacionales de vivienda social, que genera aislamiento y dificultades para allegar los recursos para garantizar el bienestar material y psicológico de sus habitantes (que invierten en virtud de su aislamiento recursos económicos importantes en movilidad), ello se multiplica en el caso de las personas con discapacidad, generando que esta población se aísle en contra de su voluntad. La población con discapacidades y la población que padece otras formas de vulnerabilidad, van padeciendo un encarcelamiento que es producto de malas decisiones de diseño, fundamentalmente.

Todo ello contribuye a la invisibilización de estas poblaciones (Narváez y Soto, 2014), toda vez que en el abandono y la indignidad que los dejan las circunstancias, no permite que la población normalizada se percate de la magnitud de esta problemática. Ello genera luego un círculo vicioso, pues la invisibilización lleva a que sus derechos ya vulnerados, sean

Citación: NARVÁEZ TIJERINA, A. et al. Dimensiones de la adaptación de las viviendas para personas con discapacidad en México: tres estudios de caso. En: Libro de proceedings, CTV 2018. XII Congreso Internacional Ciudad y Territorio Virtual. "Ciudades y Territorios Inteligentes". UNCuyo, Mendoza, 5-7 septiembre 2018. Barcelona: CPSV, 2018, p. 193-226. 
desconocidos por las poblaciones normalizadas. A pesar de que existen normativas en el sentido de garantizar el pleno goce de los derechos de estas poblaciones, es común observar en el escenario de nuestras ciudades que estas normativas sean ignoradas hasta por las autoridades que deberían vigilar su cumplimiento.

\subsection{La dimensión del problema: trabajar desde el diseño}

La organización mundial de la salud, a través de su norma CIF (OMS, 2001), define a la discapacidad como aquel estado que "engloba las deficiencias, limitaciones en la actividad, o restricciones en la participación. La CIF también enumera Factores Ambientales que interactúan con todos estos constructos. Por lo tanto, la clasificación permite a sus usuarios elaborar un perfil de gran utilidad sobre el funcionamiento, la discapacidad y la salud del individuo en varios dominios" (OMS, 2001: 3). El espíritu de esta norma plantea la necesidad de un abordaje multidimensional de esta problemática.

A pesar de que existen importantes estudios sobre la discapacidad y la exclusión que han sido abordados desde una perspectiva cuantitativa fundamental (Córdoba-Andrade et al., 2008), hay opiniones sobre la falta de especificidad de tales aproximaciones que suponen que en "la mayoría de los países del mundo, estas investigaciones han estado dominadas por una aproximación cuantitativa....acompañada por una consideración implícita de las personas con discapacidad como un colectivo homogéneo, lo que ha arrojado resultados excesivamente generales. Quizá por ello, históricamente, las políticas públicas han tratado a las personas con discapacidad de una manera global, omitiendo en la elaboración de medidas sociales su propia especificidad" (Toboso-Martín y Rogero-García, 2012: 165).

Importantes núcleos de investigación alrededor del mundo, actualmente sugieren la incorporación de metodologías cualitativas que permitan lograr una visión más comprensiva y completa sobre los problemas que impactan a la persona discapacitada en sus relaciones sociales (Hartley y Mohammad, 2003; Horejes, 2007). Existen referentes actuales en torno a la discapacidad y sus representaciones sociales que han abordado este problema desde aproximaciones de este tipo (Díaz y Malpica, 2006) o sobre el significado de la discapacidad y sus resonancias en nuestras sociedades, abordado desde la filosofía del derecho; utilizando al análisis crítico de textos filosóficos, jurídicos y de corpus legales como su aproximación fundamental (Martínez, 2011).

Para este estudio nos inclinamos hacia esta perspectiva, tanto por el hecho de que los resultados obtenidos por estos medios puedan lograr una mejor adaptación a las condiciones locales y a los problemas concretos de las personas discapacitadas, como porque desde el diseño arquitectónico y urbano esta clase de aproximaciones son tradicionales. En los estudios sobre la arquitectura y la ciudad se usan diferentes técnicas cualitativas según sea el escenario o hechos que se estudien: "el estudio de casos se usa si se requiere un análisis intensivo y profundo, los análisis históricos cuando existen fuentes documentales del pasado como evidencia... los estudios sobre arquitectura y urbanismo prefieren los análisis históricos, los análisis de fuentes documentales, los estudios de caso y los análisis de edificios y conjuntos urbanos, principalmente" (Narváez, 2011: 51-52).

Durante el año 2014 emprendimos la tarea de conocer el grado de adaptación de las viviendas sociales producidas en serie por grandes constructores de viviendas al uso por parte de personas con discapacidad, tomando como escenario las viviendas nuevas y ya ofrecidas en mercado en el área metropolitana de Monterrey.

Citación: NARVÁEZ TIJERINA, A. et al. Dimensiones de la adaptación de las viviendas para personas con discapacidad en México: tres estudios de caso. En: Libro de proceedings, CTV 2018. XII Congreso Internacional Ciudad y Territorio Virtual. "Ciudades y Territorios Inteligentes". UNCuyo, Mendoza, 5-7 septiembre 2018. Barcelona: CPSV, 2018, p. $193-226$. 
Los grandes constructores de viviendas en México, que prácticamente controlan todo el mercado, producen la vivienda a segmentos de la población que identifican a través de sus niveles de ingreso, llegando a proyectos tipo que suelen aplicar sin grandes variaciones a un gran número de localizaciones en el país. Tanto los constructores como las entidades financiadoras y el gobierno, se apoyan en esta simple concepción de los usuarios (reducidos así a ser consumidores), para planear, desde las estrategias de producción, hasta el diseño de las unidades.

Básicamente las diferencias entre los segmentos de viviendas que construyen estos grandes productores, se relacionan con las dimensiones de la vivienda, que se expresa en el tamaño del lote de terreno en que se construye, en el programa arquitectónico desarrollado (cuántas habitaciones tendrá) y en las dimensiones finales de las viviendas expresadas en metros cuadrados $\left(\mathrm{m}^{2}\right)$. Aunque existen diferencias de calidad de ciertos elementos de acabados, como el piso, las puertas, la calidad de ventanas y herrajes, por ejemplo, el resultado final ofrecido a mercado realmente expresa mínimas variaciones.

Hay aspectos simbólicos también que impactan al precio de las unidades nuevas ofrecidas, que hacen más deseables a unas viviendas sobre otras, que en general tienen que ver con el prestigio de la localización, mismo que se relaciona con las amenidades ambientales asociadas a dicha localización y a la adaptación de la vivienda al clima, que evidentemente en parte se relaciona con la localización misma (Fitch y Morillón, 2001). En general, estas variables asociadas al precio final de la unidad no generan grandes diferencias de las viviendas ofrecidas con respecto al resto del mercado, más que por los valores que describíamos arriba.

Ello hizo relativamente fácil identificar los casos de estudio. Decidimos enfocarnos a tres segmentos de vivienda, que identificamos a través de su precio de venta al público, según los datos disponibles en el fraccionamiento. Analizamos los Desarrollos Cumbres Diamante, en el municipio de Monterrey, desarrollado por la empresa JAVER, y en este conjunto el modelo Ónix Diamante; en el municipio de García, también de JAVER, el desarrollo Valle de San Blas, y el modelo Albatros Elite y en el municipio de Benito Juárez el conjunto Praderas de Oriente, y en éste el modelo: T43, Desarrollado por la empresa RUBA (figura 1).

Figura 1. Localización de los Desarrollos con las viviendas estudiadas

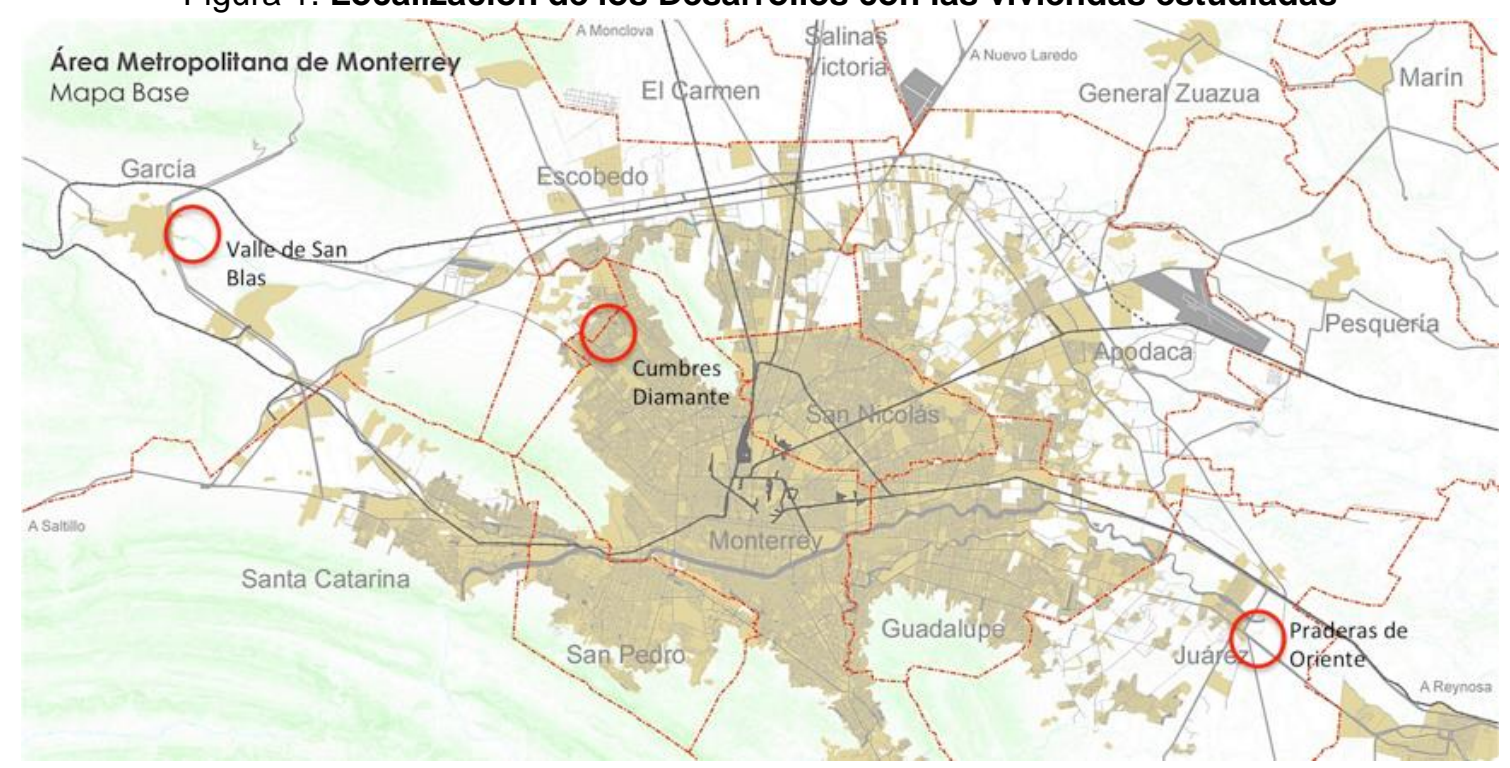

Fuente: Archivo del Centro de Desarrollo Metropolitano y Territorial-ITESM

Citación: NARVÁEZ TIJERINA, A. et al. Dimensiones de la adaptación de las viviendas para personas con discapacidad en México: tres estudios de caso. En: Libro de proceedings, CTV 2018. XII Congreso Internacional Ciudad y Territorio Virtual. “Ciudades y Territorios Inteligentes". UNCuyo, Mendoza, 5-7 septiembre 2018. Barcelona: CPSV, 2018, p. 193-226. 
En el estudio se buscó analizar desde una casa habitación de una recámara y de un nivel, hasta una casa habitación de tres recámaras y de 2 niveles, lo que representa en la oferta de Monterrey los extremos en cuanto a la vivienda social.

Para realizar el análisis se recopiló información de los proyectos arquitectónicos directamente en las empresas, luego se hizo un reconocimiento de campo en cada conjunto y verificamos las dimensiones de proyecto. Se realizó un levantamiento fotográfico tanto de las viviendas estudiadas como de los fraccionamientos y se llevaron a cabo entrevistas a habitantes de cada conjunto habitacional.

Con la información verificada se construyeron modelos en dos dimensiones en planta y en corte y en tres dimensiones utilizando el programa AutoCAD versión 2014. Estos modelos fueron analizados antropométrica y ergonómicamente utilizando el manual de Panero y Zelnik (1984) y el del IMSS (1993).

El fin del análisis fue detectar las principales áreas de conflicto de acuerdo con los requerimientos específicos de habitabilidad de cada forma de discapacidad. Con los resultados de los análisis se construyó una tabla en la que se enumeraron los problemas antropométricos y ergonómicos encontrados y estableciendo cómo éstos afectaban a los grupos de población objetivos del estudio. Las personas con discapacidad se agruparon mediante la clasificación del IMSS. Ello se hizo con el fin de contar con dimensiones que nos permitieran ulteriormente jerarquizar de diversas maneras los problemas encontrados y a la población afectada, para a través de esto encontrar soluciones viables en cuanto a la adaptación de las viviendas existentes.

A la tabla de problemas se le añadieron dos grupos humanos más: ancianos de 65 años o más y niños de entre 3 y 11 años de edad, pues encontramos que una gran cantidad de los problemas que están presentes en las viviendas cuando las usan personas con diversas discapacidades, también lo están cuando los usuarios son ancianos o niños pequeños. Esta medida sirvió para mostrar en qué medida las viviendas sociales actualmente afectan a la población usuaria.

Como muestra de ello encontramos que si sumamos a la población de personas discapacitadas a los ancianos y a los niños, tenemos, según el censo de 2010, 1 millón 181 mil 127 personas, lo cual representa el $27 \%$ de la población de la metrópoli, si además agregamos a las familias de estas personas ya estamos tratando con una población cercana a la mitad de los habitantes de toda el área metropolitana. Lo que da cuenta por sí solo de la dimensión de los problemas que describimos.

Con la lista jerarquizada de problemas arquitectónicos se procedió a ir solucionando arquitectónicamente cada problema mediante la remodelación arquitectónica de las viviendas en los modelos elaborados. La directriz que se siguió fue la de conseguir el resultado óptimo (eliminar cada problema) con la menor inversión posible. En algunos casos un rediseño del amueblamiento bastaba para solucionar algunos problemas menores, pero en otros casos se imponía crecer la superficie de terreno asignada a la unidad proyectada.

Planteamos que la remodelación arquitectónica proyectada fuera la solución óptima en el menor precio posible por dos razones: Primero porque era necesario solucionar todos los problemas, es decir llegar a unas soluciones óptimamente adaptadas, y segundo porque era necesario saber el costo de una adaptación total. 
Sabemos por experiencias de organizaciones civiles preocupadas por el bienestar de las personas con discapacidad, que la mayor parte de las viviendas sociales en las que habitan personas con discapacidad o vulnerables, están en una condición tal que el llegar a un óptimo absoluto resulta sumamente difícil o francamente fuera del alcance financiero de las familias que las habitan. A lo mucho que se llega mediante acciones de remodelación muy puntuales es a soluciones aceptables. Nuestro objetivo fue el llegar a estos modelos óptimos porque nuestro fin es exponer las dimensiones de un problema que crece día con día, con cada nueva construcción que no está bien adaptada, de cara a la carencia de normativas con las cuales trabajar en México en este momento.

Con los proyectos nuevos de las unidades conseguimos unos nuevos costos de vivienda, lo que da cuenta de lo que es mínimamente necesario hacer si queremos viviendas que sean aptas para que todos puedan habitarlas. Por medio de las entrevistas conseguimos darnos cuenta, además, de cuáles aspectos del diseño urbano de los conjuntos habitacionales podrían ser mejorados y de qué maneras, de cara a conseguir entornos urbanos mejor adaptados.

Como continuación de esta aproximación experimental planteamos otro ejercicio a partir de los análisis hechos a las viviendas, consistente en volver sobre el rediseño de dos de las tres viviendas escogidas para este estudio, pero ahora tratando de no rebasar los límites impuestos por los linderos de los terrenos máximos para cada proyecto original. Partimos en este segundo experimento de la premisa de una forma de urbanización semejante a las formas actuales en su densidad, además de que necesitábamos entender la diferencia de volumen grueso de inversión para conseguir una adaptación "total" de las viviendas sociales edificadas en la última década en México y que hubieran sido realizadas bajo unos criterios semejantes a los de las viviendas que analizábamos, sólo para fines ilustrativos.

Parte de esta experiencia consistió en un ejercicio vivencial que nos propuso la organización estudiantil UNIDEA, de la Universidad Autónoma de Nuevo León, que agrupa a las personas con discapacidad de la institución y que se encarga, entre otras cosas, de llevar a cabo programas para crear conciencia sobre la integración necesaria de las personas con discapacidad a todos los ámbitos de la vida universitaria. Ellos han desarrollado una iniciativa de concientización que consiste en hacer que una persona sin discapacidad o vulnerabilidad, desarrolle todas sus actividades de la jornada usando una silla de ruedas.

La perspectiva que se consigue sobre los problemas después de esta experiencia resultó ser asombrosamente diferente, lo que ayudó bastante al equipo de trabajo durante el trabajo de campo con las unidades de vivienda analizadas, para ser más sensibles a los problemas que podrían experimentar las personas discapacitadas en éstas.

\section{Resultados de los experimentos}

\subsection{Del análisis al primer experimento}

Enseguida se presenta la tabla que resume el estado actual de las viviendas analizadas, con los problemas encontrados y las poblaciones que resultan afectadas por éstos (Tabla 1):

Citación: NARVÁEZ TIJERINA, A. et al. Dimensiones de la adaptación de las viviendas para personas con discapacidad en México: tres estudios de caso. En: Libro de proceedings, CTV 2018. XII Congreso Internacional Ciudad y Territorio Virtual. "Ciudades y Territorios Inteligentes". UNCuyo, Mendoza, 5-7 septiembre 2018. Barcelona: CPSV, 2018, p. 193-226. 
Tabla 1. Problemas y poblaciones afectadas en los casos estudiados

\begin{tabular}{|c|c|c|c|c|}
\hline PROBLEMAS ENCONTRADOS & $\begin{array}{l}\text { Niños } \\
3 \text { a } 11 \\
\text { años } \\
775998 \\
\text { hab. }\end{array}$ & $\begin{array}{l}\text { Ancianos } \\
65 \text { y más } \\
274671 \text { hab. }\end{array}$ & $\begin{array}{l}\text { Personas con } \\
\text { discapacidad } \\
\text { motriz } \\
89279 \text { hab. }\end{array}$ & $\begin{array}{l}\text { Personas con } \\
\text { discapacidad } \\
\text { visual } \\
41179 \text { hab. }\end{array}$ \\
\hline Espacio reducido entre mobiliario & $\bullet$ & $\bullet$ & $\bullet$ & $\bullet$ \\
\hline Puertas con apertura obstruida & $\bullet$ & $\bullet$ & $\bullet$ & $\bullet$ \\
\hline Escalonamientos irregulares & $\bullet$ & $\bullet$ & $\bullet$ & $\bullet$ \\
\hline Mal diseño de la escalera & $\bullet$ & $\bullet$ & $\bullet$ & $\bullet$ \\
\hline Espacios muertos & $\bullet$ & $\bullet$ & $\bullet$ & $\bullet$ \\
\hline Altura de cajones y alacenas & $\bullet$ & $\bullet$ & $\bullet$ & $\bullet$ \\
\hline Escalera sin descanso & & $\bullet$ & $\bullet$ & $\bullet$ \\
\hline Altura de perillas y manijas de ventana & $\bullet$ & $\bullet$ & $\bullet$ & $\bullet$ \\
\hline Altura de barandales y muretes & $\bullet$ & $\bullet$ & $\bullet$ & $\bullet$ \\
\hline Altura de antepecho de ventana & $\bullet$ & $\bullet$ & $\bullet$ & \\
\hline Peraltes y huellas de escalera & $\bullet$ & $\bullet$ & & $\bullet$ \\
\hline Dimensiones del patio/área verde & $\bullet$ & $\bullet$ & $\bullet$ & \\
\hline Altura de contactos y apagadores & $\bullet$ & $\bullet$ & $\bullet$ & \\
\hline $\begin{array}{l}\text { Dimensiones de cajón de } \\
\text { estacionamiento }\end{array}$ & & $\bullet$ & $\bullet$ & $\bullet$ \\
\hline Altura de lavadero & $\bullet$ & $\bullet$ & $\bullet$ & \\
\hline $\begin{array}{l}\text { Altura propia de mesas, sillas, sofá y } \\
\text { tabla de cocina }\end{array}$ & $\bullet$ & $\bullet$ & $\bullet$ & $\bullet$ \\
\hline $\begin{array}{l}\text { Altura del techo en relación a la } \\
\text { escalera }\end{array}$ & & $\bullet$ & & $\bullet$ \\
\hline Distribución del mobiliario & & $\bullet$ & $\bullet$ & $\bullet$ \\
\hline Falta de rampas & & $\bullet$ & • & $\bullet$ \\
\hline Diseño de clóset & & $\bullet$ & $\bullet$ & \\
\hline Falta de barandales y barras de apoyo & & $\bullet$ & $\bullet$ & $\bullet$ \\
\hline Pasillos, patios y banquetas reducidos & & $\bullet$ & $\bullet$ & $\bullet$ \\
\hline $\begin{array}{l}\text { Sitios sin posibilidad de giros en silla } \\
\text { de ruedas }\end{array}$ & & • & • & \\
\hline Ancho de puertas a partir de $75 \mathrm{~cm}$ & & $\bullet$ & $\bullet$ & \\
\hline Tipos de regadera & & $\bullet$ & $\bullet$ & \\
\hline Dimensiones del baño & & $\bullet$ & $\bullet$ & \\
\hline Sin piso antiderrapante & & $\bullet$ & & $\bullet$ \\
\hline Espacio para perro guía & & & & $\bullet$ \\
\hline Indicaciones en Braille & & & & • \\
\hline $\begin{array}{l}\text { Falta de texturas indicativas en piso y } \\
\text { ruta táctil }\end{array}$ & & & & • \\
\hline
\end{tabular}

Fuente: Elaboración propia

Citación: NARVÁEZ TIJERINA, A. et al. Dimensiones de la adaptación de las viviendas para personas con discapacidad en México: tres estudios de caso. En: Libro de proceedings, CTV 2018. XII Congreso Internacional Ciudad y Territorio Virtual. "Ciudades y Territorios Inteligentes". UNCuyo, Mendoza, 5-7 septiembre 2018. Barcelona: CPSV, 2018, p. 193-226. 
A través de la Tabla 1 podemos ver los problemas principales que encontramos en las viviendas analizadas. Es posible notar que en primera instancia, éstos se relacionan con el tipo de discapacidad que presente la persona. Esto determinará las principales obstrucciones que le afectarán. Al partir de un análisis antropométrico y ergonómico, los problemas tienen un componente dimensional que es muy básico.

Gran parte de los problemas que presentan las viviendas tienen que ver con espacios reducidos para la libre circulación: por ejemplo, puertas demasiado angostas como para que una persona en silla de ruedas o desplazándose con muletas pueda pasar a través de éstas; espacio insuficiente para que una silla de ruedas pueda dar vuelta, espacio sumamente reducido entre el mobiliario, que impide la circulación; hasta la presencia de escalones que impedirían el libre tránsito de sillas de ruedas o el que solamente existan escaleras que comuniquen las dos plantas de dos de los tipos de viviendas analizadas (Figura 2).

Figura 2. Modelo de vivienda Ónix Diamante. Fraccionamiento Cumbres Diamante, en Monterrey
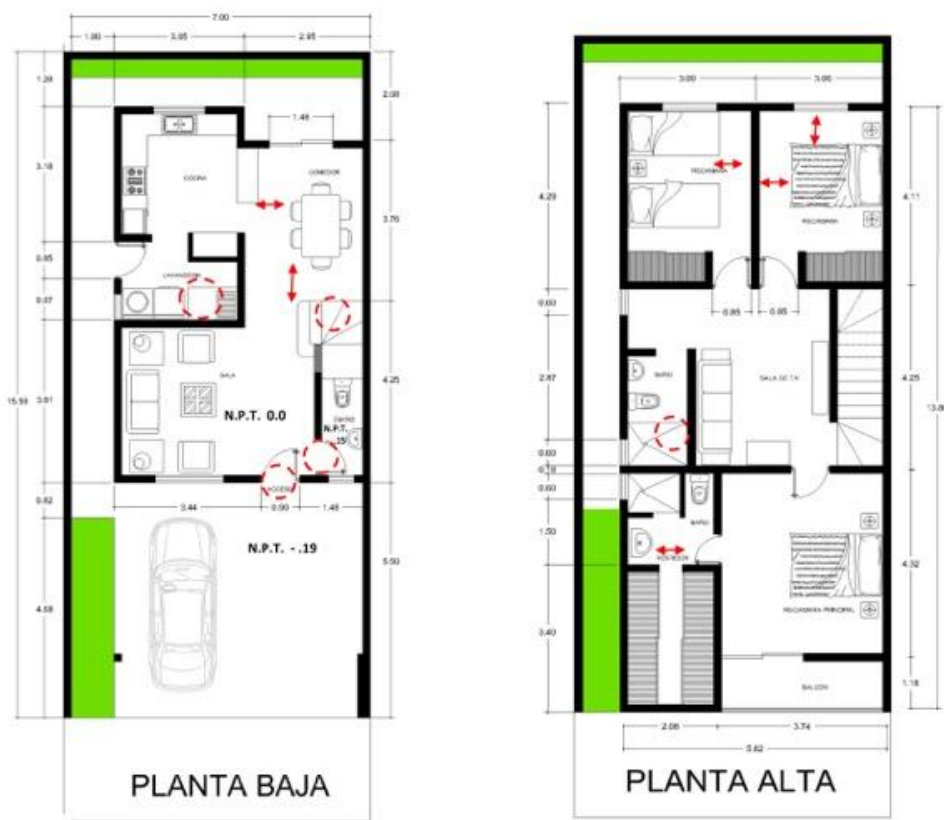

Nota: De acuerdo al levantamiento de campo se muestran las zonas con problemas mayores. Fuente: Elaboración propia

Encontramos que pese a que deberían de ser considerados otros criterios de dimensionamiento de los espacios o de elementos de la construcción (algunos fabricados en serie exprofeso para estos conjuntos de viviendas), éstos no son tomados en cuenta por los constructores. El ampliar las puertas, por ejemplo, tras nuestro análisis arquitectónico, resultaba ser de las estrategias menos costosas y que menos afectarían al diseño original, redundando en una reducción sustancial de los problemas que actualmente presentan estas viviendas. Pero esto no es visto como un recurso viable por los desarrolladores.

También hallamos que existen errores de diseño muy básicos relacionados con la posición y dimensiones de herrajes, manijas, zoclos y de diseño de mobiliario, que generan una mala adaptación. Por ejemplo, fue común ver que hay posiciones de las perillas de las puertas que son altas para que sean accionadas por personas en sillas de ruedas o por gente de baja estatura; que el diseño mismo de algunos de los elementos de mobiliario fijo de cocinas y 
lavanderías no consideran la posición de aproximación de personas que usen sillas de ruedas, siendo inutilizables, que las alturas y posiciones de ciertos gabinetes de guarda en cocinas, lavandería y roperías quedan fuera del alcance de personas en sillas de ruedas y personas de estatura baja.

Uno de los más grandes problemas de adaptación, se encuentra en los baños, ya que con muy pocas excepciones, este espacio no cuenta con dimensiones adecuadas para llevar a cabo movimientos, ni el mobiliario es adecuado (Figura 2).

Figura 3. Ejemplo de baño y pasillo en la vivienda del desarrollo Valle de San Blas, en el municipio de García

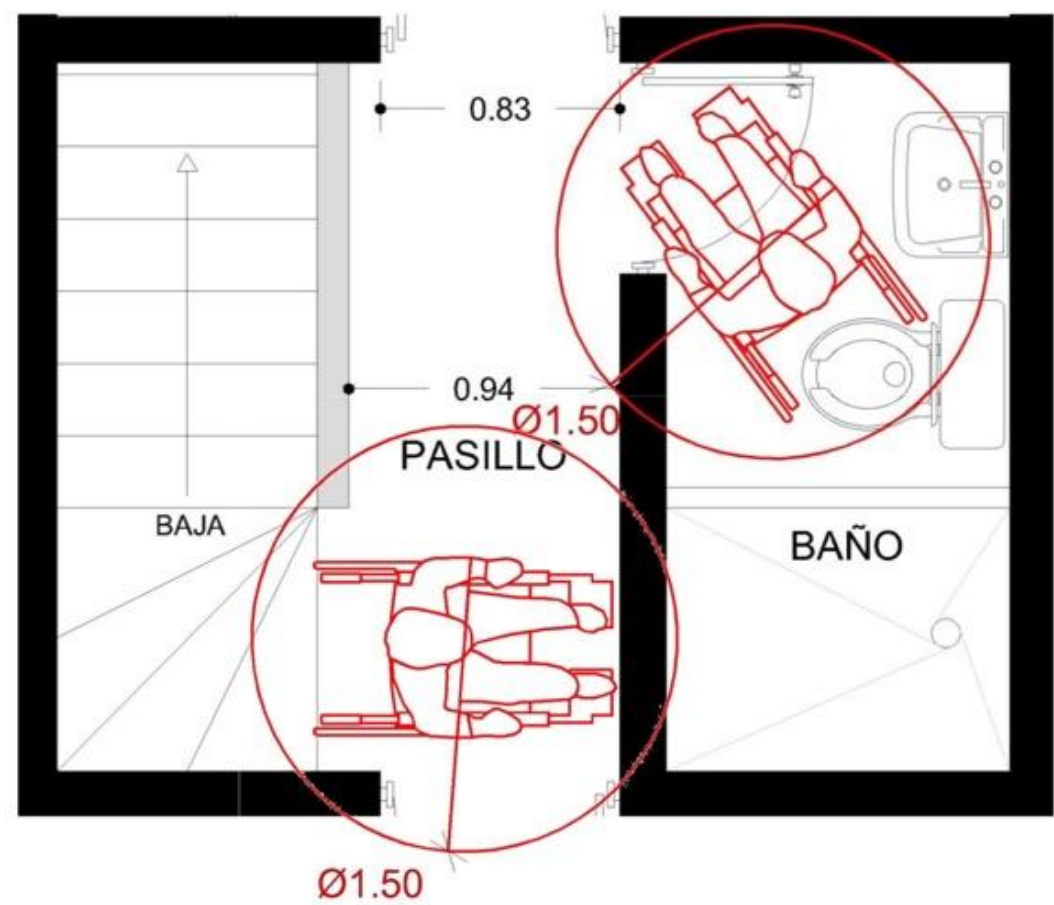

Fuente: Elaboración propia

También pudimos percatarnos de que otra parte de los problemas de diseño de estas viviendas, tiene que ver con aspectos sensoriales, que directamente se derivan de la clase de discapacidad que presente cada persona, pero que pueden llegar a ser fuentes de afectación para otros usuarios. En general estos problemas sensoriales se relacionan con tres aspectos del diseño de las viviendas: la información que los elementos de la construcción puedan brindar a usuarios discapacitados, la facilidad con que una persona discapacitada pueda establecer relaciones visuales y auditivas entre el interior y el exterior de su vivienda (conectarse con el medio urbano, obtener informaciones del exterior) y con la calidad y amenidad ambiental que pueda encontrar un usuario con muy poca o nula movilidad en el interior de su vivienda sin depender de tecnologías de conexión remota.

Un análisis detallado de las viviendas probó la existencia de grandes barreras visuales relacionadas con las medidas de la construcción de las aberturas (Figuras 3 y 4), que limitan en gran medida la vista al exterior para ciertas formas de discapacidad, lo que tiene importantes efectos en lo que se pueda en un momento dado saber del exterior, o que impiden la comunicación, el cuidado de los niños, etc.

Citación: NARVÁEZ TIJERINA, A. et al. Dimensiones de la adaptación de las viviendas para personas con discapacidad en México: tres estudios de caso. En: Libro de proceedings, CTV 2018. XII Congreso Internacional Ciudad y Territorio Virtual. "Ciudades y Territorios Inteligentes". UNCuyo, Mendoza, 5-7 septiembre 2018. Barcelona: CPSV, 2018, p. $193-226$. 
Figura 4. Corte longitudinal de vivienda, mostrando sus relaciones visuales con el medio urbano circundante para un usuario en silla de ruedas. Desarrollo Valle de San Blas

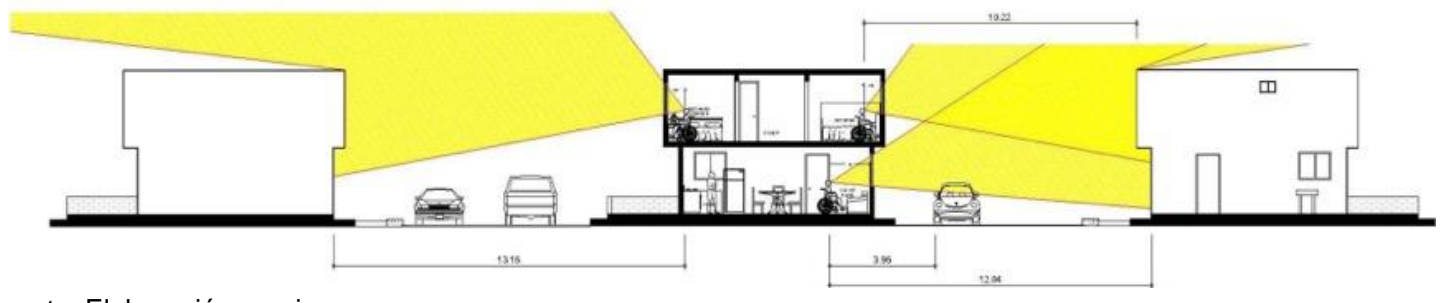

Fuente: Elaboración propia

Figura 5. Corte en detalle de un área de trabajo en la vivienda Albatros Elite del desarrollo Valle de San Blas

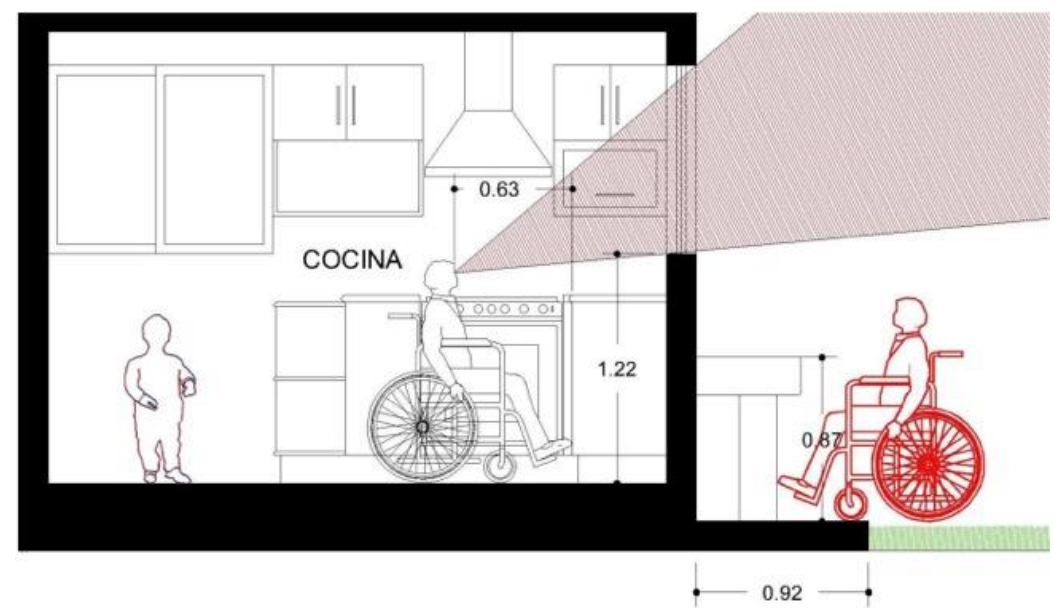

Fuente: Elaboración propia

El estudio de campo reveló que no existen señales táctiles que puedan informar a los usuarios ciegos o débiles visuales sobre proximidad de cambios de nivel en superficies de piso, por ejemplo, ni señales braille (en el fraccionamiento y en el exterior de las viviendas) que informen a visitantes con estas formas de discapacidad para que puedan orientarse adecuadamente. También pudimos percatarnos a nivel del exterior urbanizado, que existen barreras al paso libre en banquetas, producto de algunas infraestructuras urbanas mal construidas.

En su estado de entrega como casas nuevas a los usuarios las viviendas no suelen ofrecer gran amenidad visual, la mayor parte del "buen diseño" suele concentrarse en la fachada que da a la calle, el resto de la casa es normalmente bastante parco. Ello puede relacionarse con una filosofía de venta que traslada la responsabilidad de decorar al comprador, y que tiene muchas razones para seguirse llevando a cabo, pero, si el usuario final no decora y por razones de discapacidad o enfermedad tenga la necesidad de permanecer un gran tiempo sin movimiento, el encierro en esas condiciones puede llegar a ser una fuente de sufrimiento que podría disminuirse con un mejor diseño arquitectónico.

Tras haber realizado un análisis muy detallado de las viviendas, procedimos a rediseñar los modelos, tratando de llegar a un óptimo. Definimos ese óptimo de diseño como el resultado arquitectónico que solucionara en su totalidad la lista de problemas encontrados en el análisis, aún y que el grupo de personas discapacitadas fuese una cantidad muy reducida, pensamos que debía ser atendida en nuestro proyecto. Esta filosofía de diseño, que llamamos en el laboratorio "diseño democrático e incluyente", en la realidad actual de la construcción de

Citación: NARVÁEZ TIJERINA, A. et al. Dimensiones de la adaptación de las viviendas para personas con discapacidad en México: tres estudios de caso. En: Libro de proceedings, CTV 2018. XII Congreso Internacional Ciudad y Territorio Virtual. "Ciudades y Territorios Inteligentes". UNCuyo, Mendoza, 5-7 septiembre 2018. Barcelona: CPSV, 2018, p. 193-226. 
viviendas en Monterrey es poco practicada. Los diseños suelen hacerse según un criterio que privilegia a adultos jóvenes sin discapacidad ni vulnerabilidad alguna. En privado, suele ser despreciado al usuario discapacitado, tanto por diseñadores como por constructores, argumentando el poco peso demográfico que representan esta clase de compradores de vivienda. El diseño democrático e incluyente está orientado a atender a todos no en función de su poder de compra (como individuos o como grupos), sino en función de su derecho como usuarios. Un principio básico de esta manera de diseñar es el considerar que las personas tenemos una igualdad fundamental en cuanto a nuestros derechos, lo que lleva a la conclusión necesaria de que hay que atender a todos por igual. Quizás esto no implica en la práctica hacer que todos los diseños presenten una adaptación total desde su construcción, pero lo que sí implica es que los diseños sean realizados con una tolerancia dimensional tal que puedan ser adaptados fácilmente. Realizar diseños más flexibles parece ser una buena estrategia de cara a lograr esto.

También puede implicar que la amenidad, la variedad de estímulos que la vivienda ofrezca al usuario, la capacidad de que la construcción permita al usuario relacionarse con el exterior y poderse comunicar (hablar, entender, ver) o la belleza intrínseca del diseño, pueden ser concebidas no como valores agregados del diseño en sí, sino como atributos que harán que todas las necesidades de todos los usuarios potenciales sean incluidas. A estos atributos habría que pensarlos como una parte de la accesibilidad universal que no deben por ningún motivo dejarse de lado.

Otra directriz para el diseño, como se mencionó antes, fue la de lograr el óptimo a partir del menor costo posible, pues de este modo podríamos, a través del nuevo diseño, establecer mediante la escala del valor dinero, un valor objetivo del grado de lejanía de las viviendas actuales estudiadas, con un diseño óptimo en unas condiciones similares. Las figuras 5,6 y 7 muestran algunos de los resultados a los que se llegó en este proceso. En el primer caso se puede ver la necesidad de ampliar la vivienda en sus dimensiones en planta, para que la mayor parte de las obstrucciones sean eliminadas.

\section{Figura 6. Planta actual y rediseñada de la vivienda T43 en el fraccionamiento Praderas de Oriente, en Juárez}
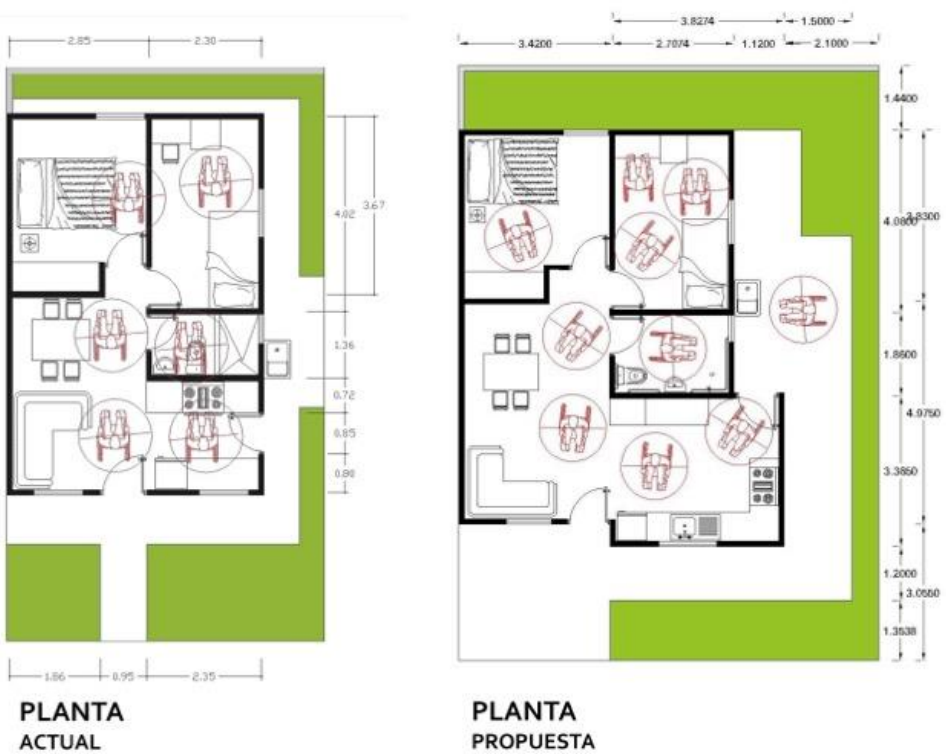

PLANTA

PROPUESTA

Fuente: Elaboración propia

Citación: NARVÁEZ TIJERINA, A. et al. Dimensiones de la adaptación de las viviendas para personas con discapacidad en México: tres estudios de caso. En: Libro de proceedings, CTV 2018. XII Congreso Internacional Ciudad y Territorio Virtual. "Ciudades y Territorios Inteligentes". UNCuyo, Mendoza, 5-7 septiembre 2018. Barcelona: CPSV, 2018, p. 193-226. 
En el segundo caso puede verse la necesidad de rediseñar las dimensiones de las ventanas de modo que permita una mayor visibilidad del exterior a los usuarios en sillas de ruedas o de estatura reducida. El primer caso exige un cambio sustancial en cuanto a las dimensiones del terreno de construcción y de la casa, en el segundo caso, exige solamente mayor cuidado en el dimensionamiento de los vanos.

Figura 7. Rediseño de la vivienda Albatros Elite considerando una mejor relación de los usuarios con el entorno urbano cercano

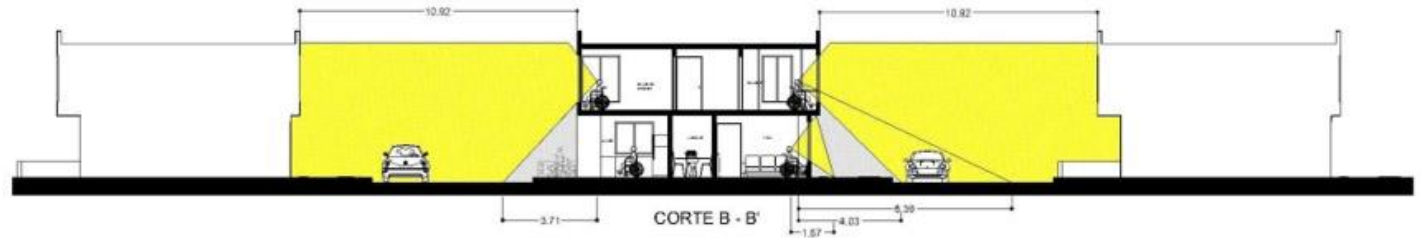

Fuente: Elaboración propia

En el tercer caso puede verse cómo se llegó a una buena adaptación por medio de pequeños cambios en el diseño, no obstante que por las características del programa que se desarrolla en dos plantas, la capacidad de adaptación de la vivienda requirió del uso de ayudas tecnológicas.

El rediseño en detalle de las viviendas seleccionadas fue realizado área por área y considerando que la vivienda adaptada se ajustara lo mejor posible a las condiciones actuales de programa arquitectónico, como a las condiciones de terreno y de distribución. Esto se hizo pensando no tanto en llegar a un nuevo óptimo, como para evaluar a las propuestas existentes en torno a la calidad de su diseño y su flexibilidad de adaptación.

Figura 8. Planta baja actual (izq.) y rediseñada (der.) de la vivienda Ónix Diamante en el fraccionamiento Cumbres Diamante, en Monterrey

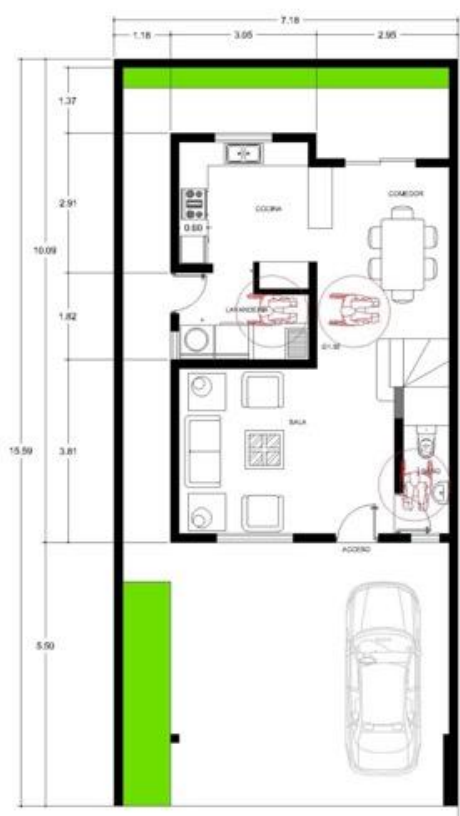

PLANTA BAJA

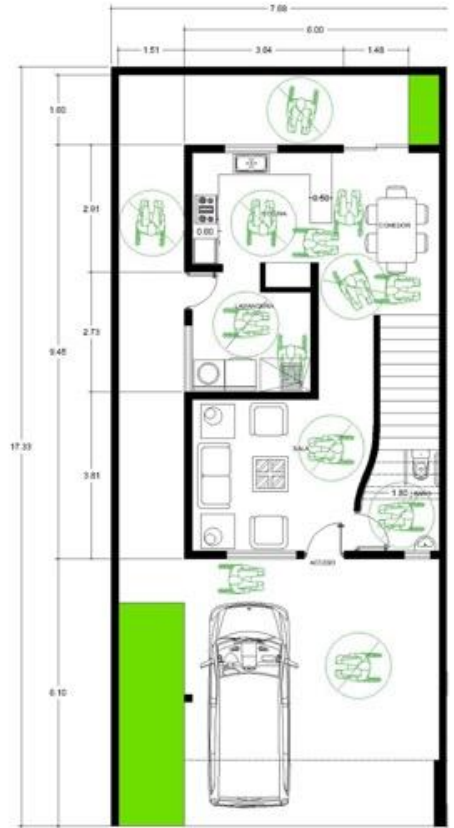

PLANTA BAJA

Fuente: Elaboración propia

Citación: NARVÁEZ TIJERINA, A. et al. Dimensiones de la adaptación de las viviendas para personas con discapacidad en México: tres estudios de caso. En: Libro de proceedings, CTV 2018. XII Congreso Internacional Ciudad y Territorio Virtual. "Ciudades y Territorios Inteligentes". UNCuyo, Mendoza, 5-7 septiembre 2018. Barcelona: CPSV, 2018, p. $193-226$. 
De los rediseños elaborados a través del primer experimento aprendimos algunas lecciones importantes: en primer lugar, que las soluciones desarrolladas por las empresas están tan bien ajustadas a unas dimensiones mínimas, tanto de terreno como de construcción, que llegar a un óptimo partiendo de los diseños originales es sumamente difícil. Esto nos ha llevado a reflexionar en torno al diseño adaptado para las personas con discapacidad, en el sentido de que con las viviendas actuales en mercado, llegar a una adaptación total puede resultar en muchos casos una tarea imposible o enormemente costosa, comparando este coste con el de adquisición de la vivienda nueva.

En segundo lugar, que la flexibilidad de los diseños actuales es muy pobre. Los diseños están tan bien ajustados (quizás porque ya se llegó a un "óptimo de programa y costo") que cualquier movimiento que se haga para mejorar aspectos de funcionamiento resulta en el deterioro del funcionamiento de áreas adyacentes, lo que reduce el margen de acción al realizar el ejercicio de rediseñar 0 al remodelar realmente la vivienda ya que se ha adquirido.

La Tabla 2 muestra sucintamente las diferentes dimensiones de los cambios que es necesario hacer a cada uno de los modelos estudiados para que resulten completamente adaptados para que puedan ser habitadas por personas con discapacidad. Sobre la base de un análisis detallado de los cambios efectuados a los modelos de vivienda estudiados establecimos unos nuevos costos, como si se produjera una vivienda nueva. En los casos en que había problemas por la presencia de obstáculos muy grandes al diseño para personas con discapacidad, nos decantamos por una solución de base tecnológica que significara un menor costo de producción que el ajuste al diseño.

Un caso concreto de ello lo representó la presencia de escaleras en dos de los modelos de vivienda estudiados. Las escaleras son un obstáculo muy difícil de sortear sin ayuda para una persona discapacitada que use silla de ruedas. Una opción que no haga uso de aditamentos mecánicos para sustituir a este elemento, tradicionalmente ha sido la construcción de rampas especialmente adaptadas, tanto en su longitud como en su pendiente para que puedan ser usadas por personas en sillas de ruedas sin ayuda de un tercero.

Una rampa, por su desarrollo resultó en los dos casos poco costeable dadas las dimensiones del terreno con el que se contaba, aunque era posible plantear una propuesta de crecimiento de la superficie del terreno de la vivienda, la dimensión del terreno necesaria era lo suficientemente grande, junto con el costo mismo de edificación de la rampa, que superaba con mucho la inversión necesaria para conseguir una solución que utilizara ayuda mecánica, como un elevador o una plataforma inclinada de desplazamiento.

Tabla 2. Comparación de diversas dimensiones de las viviendas estudiadas, frente a las mismas dimensiones de las propuestas realizadas durante el primer experimento

\begin{tabular}{|l|l|l|l|l|l|l|}
\hline $\begin{array}{l}\text { Modelo } \\
\text { de } \\
\text { vivienda }\end{array}$ & $\begin{array}{l}\text { Superficie } \\
\text { de terreno } \\
\text { proyecto } \\
\text { original }\end{array}$ & $\begin{array}{l}\text { Superficie de } \\
\text { construcción } \\
\text { proyecto } \\
\text { original }\end{array}$ & $\begin{array}{l}\text { Superficie } \\
\text { de terreno } \\
\text { propuesta }\end{array}$ & $\begin{array}{l}\text { Superficie de } \\
\text { construcción } \\
\text { propuesta }\end{array}$ & $\begin{array}{l}\text { Precio de } \\
\text { mercado } \\
\text { proyecto original } \\
\text { (en pesos } \\
\text { mexicanos) }\end{array}$ & $\begin{array}{l}\text { Precio de } \\
\text { mercado } \\
\text { propuesta } \\
\text { (en pesos } \\
\text { mexicanos) }\end{array}$ \\
\hline $\begin{array}{l}\text { Ónix } \\
\text { Diamante }\end{array}$ & $111.93 \mathrm{~m}^{2}$ & $165.53 \mathrm{~m}^{2}$ & $\begin{array}{l}133.09 \mathrm{~m}^{2} \\
(+18.9 \%)\end{array}$ & $\begin{array}{l}172.79 \mathrm{~m}^{2} \\
(+4.4 \%)\end{array}$ & $\$ 1^{\prime} 344,000$ & $\begin{array}{l}\$ 1^{\prime} 649,830 \\
+22.75 \%\end{array}$ \\
\hline $\begin{array}{l}\text { Albatros } \\
\text { Elite }\end{array}$ & $71.16 \mathrm{~m}^{2}$ & $53.94 \mathrm{~m}^{2}$ & $\begin{array}{l}97.25 \mathrm{~m}^{2} \\
(+36.66 \%)\end{array}$ & $\begin{array}{l}88.12 \mathrm{~m}^{2} \\
(+63.3 \%)\end{array}$ & $\$ 550,000$ & $\begin{array}{l}\$ 948,191 \\
+72.39 \%\end{array}$ \\
\hline T43 & $98.00 \mathrm{~m}^{2}$ & $43.37 \mathrm{~m}^{2}$ & $\begin{array}{l}124.32 \mathrm{~m}^{2} \\
(+26.8 \%)\end{array}$ & $\begin{array}{l}59.16 \mathrm{~m}^{2} \\
(+36.4 \%)\end{array}$ & $\$ 277,000$ & $\begin{array}{l}\$ 377,795 \\
+36.38 \%\end{array}$ \\
\hline
\end{tabular}

Fuente: Elaboración propia 
Esta clase de adaptaciones, para conseguir una relativa independencia de la persona discapacitada, resultaron ser costosas. La adquisición de tecnología adecuada a unos cosotos razonables, osciló entre los 104 mil 310 pesos (unos 5 mil 795 euros) y 46 mil 710 pesos (aproximadamente 2 mil 595 euros), es decir una inversión que representaba como máximo un $26 \%$ y como mínimo un $12 \%$ de la inversión necesaria para el caso de la adaptación más costosa. En el caso de la adaptación menos costosa estos valores variaban entre el $34 \%$ y el $15 \%$ del valor total de la adaptación de la vivienda. No obstante, una elección cautelosa de la tecnología apropiada nos hizo ver que en ciertos casos, la instalación de los aditamentos necesarios para poner a funcionar ciertos artefactos, ocasionaba problemas de funcionamiento adyacentes a la zona en que se instalaría el artefacto de ayuda a la movilidad (lo que hacía que tuviesen que crecer áreas, con el incremento en cadena de costos).

Una revisión de las condiciones técnicas adecuadas de los artefactos salva-escaleras, nos hizo ver que el costo de los mismos se incrementaba conforme el usuario pudiera ganar más libertad (de movimientos y de construcción de adaptaciones no móviles a su vivienda), por lo que la inversión necesaria para llevar a cabo esta clase de adaptaciones vimos que representaba una porción significativa de los costes de remodelación.

\subsection{Segundo experimento}

Para esta segunda experiencia igualmente partimos de los resultados de los análisis realizados, sólo que en esta ocasión, establecimos dos premisas de diseño: que los programas arquitectónicos de las propuestas pudieran crecer con respecto a los de los modelos analizados y que el programa se mantuviera(sólo para el caso de Albatros Elite, para poder hacer una comparación aceptable), y que para el caso de Ónix Diamante, por tratarse del programa y terreno de mayor tamaño, se hiciera el rediseño usando el mismo programa arquitectónico. La segunda premisa que se propuso fue que para todos los casos se trabajaría con el área de terreno original sin agregar o quitar nada a esta superficie.

Nos dimos cuenta de que, en el primer experimento, hubo variaciones importantes en cuanto al terreno utilizado en el rediseño (en el caso mayor, el del modelo albatros elite, de más del $60 \%$ de la superficie original), pero a costa de conservar unos diagramas de funcionamiento semejantes. Para este segundo experimento, decidimos volver sobre el proceso de diseño hasta los primeros pasos, considerando sólo como condiciones fijas a la superficie de terreno, de modo que volver a hacer diagramas de funcionamiento y una revisión al programa arquitectónico fuera posible, para el proyecto de Albatros Elite, y mantener el mismo programa, conservando igualmente la misma superficie de terreno para Ónix Diamante.

Es evidente que la variación de los diagramas de funcionamiento es mínima en los proyectos que efectivamente se construyen en México actualmente, llegando en ocasiones a existir solamente variaciones estéticas en las fachadas frontales de las casas que ofrecen diversas empresas, siendo los proyectos (funcionales) casi idénticos. Por lo que se impone la necesidad de un análisis desde este nivel del proyecto con el fin de lograr mejoras sustanciales a las viviendas con el objetivo de adaptarlas a las personas con discapacidad.

En este segundo experimento partimos de ese nivel del proceso de diseño arquitectónico, con miras a lograr un óptimo funcional para la población discapacitada, pero aún con el objetivo de crear diseños del más bajo costo posible, dadas las necesidades de la población a la que atendíamos. El hecho de decidirnos por no hacer modificaciones a las superficies de los terrenos tuvo como orígenes dos consideraciones: el hecho de que en gran medida los nuevos diseños podrían caer en los casos de remodelaciones de viviendas existentes, por lo que

Citación: NARVÁEZ TIJERINA, A. et al. Dimensiones de la adaptación de las viviendas para personas con discapacidad en México: tres estudios de caso. En: Libro de proceedings, CTV 2018. XII Congreso Internacional Ciudad y Territorio Virtual. "Ciudades y Territorios Inteligentes". UNCuyo, Mendoza, 5-7 septiembre 2018. Barcelona: CPSV, 2018, p. 193-226. 
valdría la pena medir los recursos necesarios para lograr una adaptación total de un parque de viviendas existentes que hoy se encuentran lejos de ser totalmente útiles para habitantes discapacitados y por otra parte, para tener una medida real de la diferencia en el costo de las construcciones adaptadas, eliminando la variación de los costos de los terrenos, toda vez que por un efecto acumulado, variaciones de las dimensiones de los terrenos necesarios en un grupo de viviendas, afectaría la superficie de la urbanización, con lo que un cálculo directo de la variación del capital necesario para lograr el que se pudieran llevar a cabo las adaptaciones, no podría hacerse considerando solamente la inversión por parte de los moradores que decidan adaptar sus viviendas, haciendo difícil la comparación de los modelos ideales con los reales tomando en cuenta también los costos de las urbanizaciones.

El primer diseño de este segundo experimento fue encaminado a modificar profundamente el modelo Albatros Elite, se decidió cambiar el diseño en orden de lograr un máximo de eficiencia en cuanto a la movilidad interior y exterior de personas discapacitadas motrices, así como aumentar su programa de proyecto: en la planta baja se proyectó un baño de visitas, una pequeña bodega de útiles y una cochera techada. En la planta alta se agregó al programa una recámara.

En el segundo diseño se volvió a modificar el modelo Albatros Elite, pero en este caso solamente sus áreas y diagrama de funcionamiento, respetando la superficie de terreno original, como se apuntaba antes. En el tercer diseño se procedió igual, aunque el resultado de que se consiguió refleja menos libertad creativa que en el segundo diseño, no obstante que arquitectónicamente resulta mejor adaptado que el que se consiguió en el primer experimento. Lo que se obtuvo fue lo siguiente:

Tabla 3. Comparación de las viviendas estudiadas, frente a las propuestas realizadas en el segundo experimento

\begin{tabular}{|c|c|c|c|c|c|c|}
\hline $\begin{array}{l}\text { Modelo de } \\
\text { vivienda }\end{array}$ & $\begin{array}{l}\text { Superficie } \\
\text { de terreno } \\
\text { proyecto } \\
\text { original }\end{array}$ & $\begin{array}{l}\text { Superficie de } \\
\text { construcción } \\
\text { proyecto } \\
\text { original }\end{array}$ & $\begin{array}{l}\text { Superficie } \\
\text { de terreno } \\
\text { propuesta }\end{array}$ & $\begin{array}{l}\text { Superficie de } \\
\text { construcción } \\
\text { propuesta }\end{array}$ & $\begin{array}{l}\text { Precio de } \\
\text { mercado } \\
\text { proyecto } \\
\text { original (en } \\
\text { pesos } \\
\text { mexicanos) }\end{array}$ & $\begin{array}{l}\text { Precio de } \\
\text { mercado } \\
\text { propuesta } \\
\text { (en pesos } \\
\text { mexicanos) }\end{array}$ \\
\hline $\begin{array}{l}\text { Albatros } \\
\text { Elite } \\
\text { programa } \\
\text { modificado } \\
\text { terreno } \\
\text { original } \\
\text { segundo } \\
\text { experimento }\end{array}$ & $71.16 \mathrm{~m}^{2}$ & $53.94 \mathrm{~m}^{2}$ & $\begin{array}{l}71.16 \mathrm{~m}^{2} \\
( \pm 0.0 \%)\end{array}$ & $\begin{array}{l}137.21 \mathrm{~m}^{2} \\
(+154.37 \%)\end{array}$ & $\$ 550,000$ & $\begin{array}{l}1 ’ 399,035 \$ \\
(+154.37) \%\end{array}$ \\
\hline $\begin{array}{l}\text { Albatros } \\
\text { Elite } \\
\text { programa } \\
\text { original } \\
\text { terreno } \\
\text { original } \\
\text { segundo } \\
\text { experimento }\end{array}$ & $71.16 \mathrm{~m}^{2}$ & $53.94 \mathrm{~m}^{2}$ & $\begin{array}{l}71.16 \mathrm{~m}^{2} \\
(+0.0 \%)\end{array}$ & $\begin{array}{l}82.16 \mathrm{~m}^{2} \\
(+52.31 \%)\end{array}$ & $\$ 550,000$ & $\begin{array}{l}837,705 \$ \\
(+52.31) \%\end{array}$ \\
\hline $\begin{array}{l}\text { Ónix } \\
\text { Diamante } \\
\text { programa } \\
\text { original } \\
\text { Segundo } \\
\text { experimento }\end{array}$ & $111.93 \mathrm{~m}^{2}$ & $165.53 \mathrm{~m}^{2}$ & $\begin{array}{l}111.93 \mathrm{~m}^{2} \\
( \pm 0 \%)\end{array}$ & $\begin{array}{l}179.40 \mathrm{~m}^{2} \\
(+8.37 \%)\end{array}$ & $\$ 1^{\prime} 344,000$ & $\begin{array}{l}\$ 1^{\prime} 653,120 \\
+23.00 \%\end{array}$ \\
\hline
\end{tabular}

Citación: NARVÁEZ TIJERINA, A. et al. Dimensiones de la adaptación de las viviendas para personas con discapacidad en México: tres estudios de caso. En: Libro de proceedings, CTV 2018. XII Congreso Internacional Ciudad y Territorio Virtual. "Ciudades y Territorios Inteligentes". UNCuyo, Mendoza, 5-7 septiembre 2018. Barcelona: CPSV, 2018, p. 193-226. 
A través de los resultados del segundo experimento, puede verse que el proyecto de una refuncionalización con ampliación al programa arquitectónico de la casa Albatros Elite, puede costar tanto (o más) que lo que cuesta la vivienda de acuerdo con su valor de comercialización actual, como puede apreciarse en la primera línea de la tabla 3: el usuario tendría que pagar unos 850,000 pesos más a los que ya gastó por adquirir su vivienda, para hacer esta remodelación ${ }^{2}$. Al plantear este proyecto en particular, situamos el objetivo en lograr un máximo alcanzable dados los recursos máximos aceptables para una vivienda terminada (excluyendo un posible crecimiento vertical). Lo que se obtuvo fue que con una pequeña ampliación al programa arquitectónico y con una adaptación mínima para el habitante con discapacidad, se agotaba el terreno disponible, lo cual tiene repercusiones importantes al nivel del diseño urbano, como se verá.

¿Quién paga por este proyecto de re-funcionalización? De acuerdo con el planteamiento subyacente de este segundo experimento, para el caso de las personas discapacitadas, las unidades de vivienda serían concebidas por los desarrolladores no como una solución óptima sino apenas como una base de la cual partir para que sea el propio usuario el que invierta en la re-funcionalización de su vivienda. Los resultados muestran que ello puede costar el duplicar su inversión inicial, con tal de conseguir un hogar lo mejor adaptado posible.

Siempre que el costo de la adaptación se le cargueal usuario final, un volumen económico como el que se planteó en el proyecto que describe la primera línea de la tabla 3, puede ser oneroso y por lo tanto difícil de alcanzar para el comprador promedio, que frente a ello tendría que esperar un buen tiempo para empezar a plantearse la posibilidad real de remodelar su vivienda. Lo que lleva inevitablemente a considerar que gran parte de la vida útil de las casas como ésta puede transcurrir siendo inadecuada para un usuario con discapacidad. Y puede ser una de las maneras para explicar por qué se realizan adaptaciones paliativas que refuncionalizan apenas las viviendas, pero ni con ello dejan de ser incómodas.

Es notable lo que se consiguió en el segundo rediseño al modelo Albatros Elite, como puede verse en la segunda línea de la tabla 3 si se lo compara con los resultados del primer experimento (Tabla 2). Resultó que el diseño, pese a no requerir más terreno que el propuesto originalmente para este modelo de vivienda, fue notablemente más eficiente que el diseño al que se llegó en el primer experimento, con lo que se consiguió un ahorro final de más de 100 mil pesos con respecto al costo final del proyecto expuesto en la Tabla 2. ¿A qué se debe esto? La principal variación que se consiguió consistió en una estrategia diferente de diseño.

Al abstraer una forma arquitectónica a un grafo que solamente revela las relaciones de proximidad de los espacios y sus conmutaciones pueden verse interferencias, nuevas relaciones posibles que podrían devenir en diseños arquitectónicos novedosos y a la vez valiosos, etc. Cuando es analizada así la arquitectura de los grandes maestros, por ejemplo, uno puede darse cuenta que la capacidad de inventiva de éstos es bastante limitada cuando se analizan los mismos tipos de edificios de un solo autor: tal parece que el maestro ha llegado a una solución "óptima" y luego lo que hace es ir modificando la "piel" y las dimensiones del mismo objeto, que sigue siendo idéntico en un cierto nivel a sus predecesores. Esto es en ocasiones explicado como elementos del estilo o como lógica funcional. Pero el resultado es

2 Considerando la base del costo de remodelación a los precios de venta de la compañía desarrolladora, ello se hace con un fin ilustrativo únicamente. Evidentemente los costos pueden variar de acuerdo a las condiciones del mercado al que acuda el usuario y a la calidad de la obra que ejecute. 
una conmutación sin grandes variaciones entre espacios de diversos edificios, a pesar de haber sido concebidos para tiempos, contextos físicos o culturas diferentes.

Eso es algo que se ve que pasa en el proyecto de las viviendas sociales en México. Nos dimos a la tarea de re-imaginar desde esa raíz al diseño, desde sus conmutaciones y logramos un notable ahorro sin sacrificar la adaptación del diseño a las personas con discapacidad.

En el caso del rediseño de la vivienda Ónix Diamante, lo que logramos con el rediseño de Albatros Elite, no pudo ser posible: para hacer un cambio funcional y de dimensiones que consiguiera una mejora al diseño original, hubo que recurrir a la estrategia de crecer el terreno original. Ciertamente mejoró el diseño frente al conseguido en el primer experimento, pero muy poco relativamente hablando.

De esta experiencia pudimos darnos cuenta que en los extremos de este segmento de viviendas estudiadas (por sus dimensiones y precios) existe muy poco margen de flexibilidad como para conseguir una mejor adaptación, lo que nos deja como enseñanza que lo que es necesario hacer es volver a pensar estos diseños desde la raíz, lo que efectivamente tendrá repercusiones profundas en el diseño urbano también.

\section{3 ¿Qué hacer, entonces?}

Veamos en detalle lo que nos dice la tabla 2 y la 3 . Los tres modelos de vivienda estudiados son inadecuados para ser habitados por personas con discapacidad que presenten la necesidad forzosa del uso de silla de ruedas para moverse en el interior y exterior de su vivienda y son poco adecuados para el resto de las discapacidades clasificadas según el criterio que puede verse en la tabla 1, así como para las personas vulnerables. Los grados de inadecuación, sin embargo, como se ve en la tabla 2, varían. Sorprendentemente, el modelo más pequeño y más económico de los 3 (T43) no es el menos adecuado. La vivienda de la clase intermedia (Albatros Elite), resultó ser el peor diseño de los 3, de acuerdo al área de crecimiento demandada por el proyecto de adecuación realizado y a la variación final del costo de la adecuación comparado con el precio de mercado inicial.

Por otra parte, no sorprende que sea en el segmento más caro estudiado, que las adecuaciones necesarias sean las menores. Lo que puede indicar que hay una obvia relación directa entre la capacidad del diseño para adaptarse a su uso por personas con discapacidad y la superficie proyectada. Pero, por otro lado, lo contrario no parece ser correcto, la evidencia encontrada mediante el experimento 1 nos indica que el proyecto con la menor superficie fue más flexible que el del segmento inmediato superior.

Hay una relación más o menos elástica, cuando nos referimos a la capacidad de cualquier diseño de ser adaptado, entre sus características intrínsecas (el diseño en sí) y las dimensiones absolutas de construcción y de terreno disponible. Por otra parte, el análisis reveló que, en el caso de la oferta de viviendas unifamiliares, es necesario que cada unidad cuente con una reserva de terreno lo suficientemente grande para su crecimiento en caso de ser necesaria una remodelación para adecuarla a las necesidades presentes y futuras de la población discapacitada o vulnerable.

Una de las cosas que resultaron evidentes de ambos experimentos es que toda vez que las viviendas actualmente se producen considerando por encima de cualquier otra cosa un ajuste mínimo a unos estándares que limitan de manera muy importante la flexibilidad de las

Citación: NARVÁEZ TIJERINA, A. et al. Dimensiones de la adaptación de las viviendas para personas con discapacidad en México: tres estudios de caso. En: Libro de proceedings, CTV 2018. XII Congreso Internacional Ciudad y Territorio Virtual. "Ciudades y Territorios Inteligentes". UNCuyo, Mendoza, 5-7 septiembre 2018. Barcelona: CPSV, 2018, p. 193-226. 
construcciones, la posibilidad de adaptación de las unidades a las necesidades de una población tan numerosa es en la práctica un asunto si no imposible, sí tortuoso.

Se hace necesario pensar en otra clase de diseños, toda vez que la falta de flexibilidad, por ejemplo, para utilizar toda la vivienda cuando su programa arquitectónico se desarrolla en dos plantas, obliga al uso de ayudas mecánicas, que resultaron ser de un impacto importante en el costo final calculado de las adaptaciones. De nuevo, contar con una mayor superficie de terreno para el desarrollo de las viviendas unifamiliares puede ser una opción que permita el desarrollo de programas completos en una planta. Pero esto, cuando se empieza a pensar en términos de las grandes cantidades de vivienda producidas y las necesarias, dada la demanda actual y futura, puede desencadenar otra clase de problemas, ahora de carácter más urbano, por la gran demanda de tierra que implicaría el pensar en mayores terrenos. A esa gran demanda de tierra, evidentemente se suman mayores costos de infraestructuras urbanas de soporte, mayores costos de transportación urbana de personas y bienes, etc.

A través del segundo experimento pudimos atestiguar que es necesario invertir en unos mejores diseños. Pensar en que las viviendas sean adecuadas para las personas discapacitadas y vulnerables es algo evidentemente necesario, pero cuando es planteando este tema más ampliamente que el solamente solucionar eso, hay que pensar y hacer cambios más profundos aún.

Notamos que lo inadecuado de estos diseños radica en la raíz misma de esas organizaciones de espacios. Hay que pensar de maneras diferentes a los diseños. Por poner un ejemplo, argumentaremos que pese a que dogmáticamente (casi como un condicionamiento operante) los arquitectos reaccionamos agrupando los espacios en torno a un núcleo y asociamos funciones afines: de eso habla uno de los más profundos preceptos del racionalismo y funcionalismo con el que se nos ha educado. Esto, que logra importantes ahorros en la obra por la minimización de costos de tierra y la racionalización de recursos humanos y materiales a la hora de edificar (además de que se ha convertido en un modelo socialmente compartido por el gremio y por ello se ve como una forma valiosa e inteligente de proceder), a la larga hace que la gente que habite esas viviendas se mueva menos y eso a la larga tiene importantes repercusiones en la salud.

Resulta que los modelos que logran que la gente se mueva más (un esquema en donde no se procede diseñando con una organización nuclear sino dispersa, por ejemplo y en donde se alejan las funciones afines en vez de acercarlas) luego son los que mayormente fomentan la salud de los habitantes y su bienestar general, pese a lo que pudiera pensarse. Es necesario hacer más investigación en el diseño experimental para lograr nuevos óptimos que vayan sustituyendo las viejas maneras de proceder de los arquitectos, así como plantear serias campañas de concientización dirigidas tanto a los públicos especializados como a los no especializados de cara a modificar la confianza sobre unos modelos de organización espacial de los edificios de vivienda (y otros) que representan serios riesgos a la salud y bienestar de los habitantes, para mover la opinión hacia otros mejores diseños.

También es necesario investigar en el diseño sobre modelos que al agruparse en tramas urbanas, tanto ofrezcan ventajas para el fomento a la movilidad plena ( $\mathrm{y}$ a la salud en forma concomitante), como resulten en tramas urbanas de una densidad aceptable, que eviten el desenfreno de la ciudad dispersa y el encierro de la ciudad compacta, así como la posibilidad de que las personas formen comunidades: tramas que permitan a la gente salir, moverse,

Citación: NARVÁEZ TIJERINA, A. et al. Dimensiones de la adaptación de las viviendas para personas con discapacidad en México: tres estudios de caso. En: Libro de proceedings, CTV 2018. XII Congreso Internacional Ciudad y Territorio Virtual. "Ciudades y Territorios Inteligentes". UNCuyo, Mendoza, 5-7 septiembre 2018. Barcelona: CPSV, 2018, p. 193-226. 
comunicarse, pero también aislarse a voluntad, estar quietos, descansar, hacer lo que hacen habitando en ciudades; en bienestar pleno.

\subsection{Para mejorar la vivienda y su entorno}

Entonces, ¿qué es necesario que hagamos? Otra cosa que se aprendió delos experimentos que se realizaron, es que el diseño de detalle, es decir, el de las dimensiones de los elementos menores de la construcción, el de los ajustes entre elementos, el de la búsqueda de la visibilidad del interior hacia el exterior, la dimensión de las banquetas y andadores de acceso, etc., es muy poco cuidadoso actualmente. Revela ello, quizás, que los diseños que se hacen son pensados para un segmento de población que es bastante restringido, no obstante, el peso demográfico que actualmente representa la población con diversos grados de vulnerabilidad y sus familias.

Es necesario pensar más en el diseño desde los niveles de detalle, hasta los niveles urbanos, para que éste sea adecuado e incluyente para la población discapacitada. Una primera aproximación a este cambio puede realizarse desde la educación y reeducación de los diseñadores. Aunque con excepciones notables, la mayor parte de los técnicos que se encargan del diseño de las nuevas unidades de viviendas y de los fraccionamientos, no proyectan pensando en usuarios discapacitados o en el rango de edad, que les hagan personas potencialmente vulnerables. Es quizás por perseguir el objetivo de un mayor incremento del rendimiento del capital de la empresa en que laboran, que la mayor parte de su energía se concentra en reducir al máximo las dimensiones de la vivienda, de reducir el uso de tierra necesaria y de hacer muy eficiente también el uso de tierra a urbanizar.

Esto se nota, sobre todo, en la llegada a unos "óptimos" que con el tiempo van presentando cada vez menos variaciones en cuanto al diagrama de funcionamiento arquitectónico se refiere, si bien sí exhiben variaciones más o menos importantes en el diseño de su fachada frontal y en los materiales de acabados utilizados. La llegada a unos óptimos que ya no admiten grandes variaciones, ha hecho que las soluciones sean potencialmente cada vez menos flexibles, lo que redunda en el costo de adecuación de la vivienda.

Cuando estas adecuaciones se vuelven necesarias, es común que la mayor parte de los diseñadores dejen éstas a los futuros usuarios de las viviendas. El que consigan luego los usuarios una adecuación total se vuelve un asunto bastante difícil, pues, ni los diseños poseen valores de flexibilidad adecuados, ni las superficies de terrenos alcanzan, y los usuarios pueden no contar con los recursos necesarios para emprender remodelaciones totales. Con lo que se quedan la mayoría de los usuarios que sí logran intervenir su vivienda para adecuarla, es con soluciones parciales e incomodidad.

Si esto se relaciona con la calidad de los diseños, es lógico pensar que la solución estaría en el terreno del diseño (como si se tratase de una "medicina arquitectónica preventiva"). Una educación o reeducación de los diseñadores podría empezar con iniciativas como las que actualmente desarrolla UNIDEA, descrita antes en este trabajo: vivir los lugares desde la perspectiva de una persona discapacitada o vulnerable, puede ser un elemento que haga más sensibles a los diseñadores. La construcción de modelos arquitectónicos en escala real para su evaluación por diseñadores y usuarios potenciales, puede ser una buena estrategia para poner a prueba los diseños.

Citación: NARVÁEZ TIJERINA, A. et al. Dimensiones de la adaptación de las viviendas para personas con discapacidad en México: tres estudios de caso. En: Libro de proceedings, CTV 2018. XII Congreso Internacional Ciudad y Territorio Virtual. "Ciudades y Territorios Inteligentes". UNCuyo, Mendoza, 5-7 septiembre 2018. Barcelona: CPSV, 2018, p. 193-226. 
Diseñar, así, debería de conectarse más con la experimentación, alejándose de soluciones preconcebidas. La propia normativa de diseño que usan las empresas desarrolladoras, podría ponerse a pueba con estos medios, para empezarla a modificar. Es necesario entonces concebir al taller de diseño como un laboratorio de investigaciones, planteándose seriamente el hacer modelos y prototipos de nuevos edificios y sus entramados como un fin de investigación muy valioso para la educación de los especialistas y del público.

Toda vez que los diseñadores de las empresas reciben órdenes de sus superiores y sus diseños son sujetos del escrutinio de juntas dirección, de accionistas o de dueños que velan más que por la integridad de los diseños por el rendimiento del capital que estén en un momento dado arriesgando, también la educación se debería de extender hasta estas esferas. No solamente se trata de poner en la balanza cuestiones de mayores rendimientos de capital frente a la calidad intrínseca de los diseños, cosa que cala en hacer ver que la avaricia puede en un corto plazo ser beneficiosa para hacer crecer el capital, pero a largo plazo, puede terminar socavando la credibilidad de la empresa, poniendo en tela de juicio los fundamentos éticos de sus acciones y su compromiso real con la sociedad; se trata además en hacer ver que las mejores prácticas empresariales se consiguen en escenarios de una gran solidaridad con los clientes (actuales o potenciales).

En ese sentido, la calidad juega un papel importante y es lo que a los ojos de los consumidores puede hacer una diferencia durante la adquisición de un producto. Si bien en este momento puede el diseño incluyente ser un aspecto secundario para la elección residencial (con un predominio actual hacia los valores reales y sentidos de la localización, el precio del inmueble, las facilidades de financiamiento, etc.), no obstante, no debe dejarse de lado el hecho de que la población mexicana está cambiando, la vulnerabilidad física por el envejecimiento de una porción económicamente importante de la sociedad futura, puede marcar la pauta sobre lo que se podría elegir frente a necesidades que hoy pueden parecer marginales pero en un futuro realmente cercano, pueden llegar a ser valores fundamentales de elección.

Una rápida mirada al caso del abandono de conjuntos habitacionales completos en Ciudad Juárez en México durante la década pasada (Maycotte Pansza, 2007), puede darnos una pista de lo que realmente puede estar ocurriendo en el ámbito de los consumidores actuales. Ante esta problemática y una acrecrítica en los medios a las viviendas mínimas que se producían en esta ciudad fronterizapor ese tiempo, el titular del Instituto de Fomento Nacional para la Vivienda de los Trabajadores en México (INFONAVIT) tuvo que aceptar que se necesitaba ingenio y creatividad para plantearlos nuevos diseños de las viviendas mínimas y sus conjuntos (Diario de Ciudad Juárez, 03-10-2006).

Las prácticas empresariales deben reenfocarse para centrarse en los usuarios reales, con una visión de futuro, dado que, para la mayoría de las familias en nuestro país, comprar una vivienda se plantea como la adquisición de un bien muy durable, quizás como la única y mayor inversión de las familias para cubrir las necesidades habitacionales. Es posible pensar que un mayor margen de capitalización de las familias, podría inclinar la balanza hacia la adquisición de bienes que presenten una mayor calidad intrínseca.

Por otra parte, una de las cosas que se hicieron visibles en los análisis que realizamos, es que se necesita flexibilidad en el diseño y la construcción. El diseño perfectamente adaptado para su uso por personas discapacitadas, no debería de pensarse como de consumo exclusivo por esta población actual. En la práctica, por el tiempo normal de uso de la vivienda habría de pensarse en que se van a atravesar ciclos de vida en el mismo espacio, eventualidades como

Citación: NARVÁEZ TIJERINA, A. et al. Dimensiones de la adaptación de las viviendas para personas con discapacidad en México: tres estudios de caso. En: Libro de proceedings, CTV 2018. XII Congreso Internacional Ciudad y Territorio Virtual. "Ciudades y Territorios Inteligentes". UNCuyo, Mendoza, 5-7 septiembre 2018. Barcelona: CPSV, 2018, p. 193-226. 
enfermedades 0 accidentes, que pueden conducir a discapacidades temporales 0 permanentes, el propio proceso de envejecimiento de los miembros de la familia, el recibir en el hogar a nuevos miembros vulnerables (niños o ancianos), debería redundar en que como diseñadores pensáramos en el proyecto de espacios que pudieran ser transformados.

Esto se relaciona tanto con el diseño en sí y el grado de adaptabilidad que éste podría soportar (que efectivamente existan holguras, que en los arreglos funcionales no se presenten fácilmente las interferencias entre elementos construidos y flujos, etc.), como con los medios tecnológicos a través de los que se producen las viviendas actualmente. En el caso mexicano, predominan las construcciones de obra sólida (muros de tabiques de barro, de bloques de concreto, losas de concreto, pisos de concreto) tanto para los cerramientos exteriores como para las subdivisiones interiores.

Las claras ventajas de esta elección tecnológica en cuanto a duración de los inmuebles y resistencia ante elementos naturales, no parecen serlo tanto frente a la necesidad de flexibilidad que reclama el que las viviendas tengan una buena capacidad de adaptación. Una elección tecnológica basada en la utilización de elementos móviles, por ejemplo, podría ofrecer algunas ventajas para conseguir este objetivo.

De todas maneras, como resultado de nuestro trabajo de campo, se puede afirmar que una parte fundamental del conseguir unas viviendas bien adaptadas para ser habitadas por personas discapacitadas o vulnerables, es el elaborar buenos diseños. Aún con la elección de tecnologías que restrinjan de forma importante la transformación de la vivienda, un buen diseño puede anticiparse a los cambios haciéndolos poco necesarios o deseables. En cambio, una transformación tecnológica (aunque sea parcial) requiere de una mayor inversión de recursos para lograrla, e impacta a otros ámbitos de actividad (producción industrial, comercialización, etc.) requiriendo de una transformación conjunta de éstos para que la transformación tecnológica pueda hacerse visible y exhibir un impacto apreciable.

No obstante, que un cambio en el diseño parece ser una tarea fácil, para que se dé realmente y que éste impacte en los modos de concebir la organización de los espacios, es necesaria una transformación profunda de las mentalidades. El imaginario dominante de los diseñadores parece moverse en torno a unos cuantos moldes preconcebidos y una paleta estilística dada. Eso es natural, toda vez que los diseñadores son personas insertas en sociedades con valores entendidos, imágenes, ética y racionalizaciones que les orientan a la hora de tomar sus decisiones. Un cambio en el imaginario dominante requiere cambios profundos en la cultura, 0 una crisis de una magnitud tal que socave los cimientos de lo que pudiera llegar a considerarse una verdad evidente.

Cambiar el imaginario dominante sobre los "buenos diseños" acaso sea uno de los objetivos más importantes si es que se desea mejorar el estado actual de nuestras ciudades. Y eso puede ser más un asunto de educación de los diseñadores.

Una parte importante de la adaptación de las viviendas lo constituye también conseguir un buen diseño urbano. En este nivel del diseño, al igual que en el de la propia vivienda, entran en juego múltiples variables. Desde luego que una buena adaptación física de los lugares en los que las personas desarrollan sus actividades es un asunto que puede llegar a facilitar mucho la vida a una persona con discapacidad, pero esto no es todo. Actualmente, los conjuntos habitacionales en Monterrey son proyectados como unidades abiertas (como la ciudad tradicional) o cerradas (con controles de acceso, con barda perimetral), dependiendo del

Citación: NARVÁEZ TIJERINA, A. et al. Dimensiones de la adaptación de las viviendas para personas con discapacidad en México: tres estudios de caso. En: Libro de proceedings, CTV 2018. XII Congreso Internacional Ciudad y Territorio Virtual. "Ciudades y Territorios Inteligentes". UNCuyo, Mendoza, 5-7 septiembre 2018. Barcelona: CPSV, 2018, p. 193-226. 
estrato económico al que estén dirigidas. En la mayor parte de los casos, las unidades abiertas se destinan a los segmentos de viviendas de menor costo.

A esta manera de concebir los conjuntos habitacionales se suma el hecho de que son proyectados como unidades completamente habitacionales. Si bien en los conjuntos más recientes se incorporan escuelas primarias y secundarias públicas, hay una serie de servicios urbanos que están ausentes en los conjuntos nuevos. La falta de variedad puede ser un gran obstáculo para la vida de una persona vulnerable o discapacitada, por razones prácticas, la lejanía relativa de los centros de servicios urbanos con respecto a los nuevos conjuntos habitacionales, hace necesario el desplazamiento en transporte público o privado, lo que ya de por sí es un límite a la movilidad e implica el contar con medios de acceso a estos bienes 0 servicios, que pueden no estar a la mano de todos.

Otra razón práctica tiene que ver con la capacidad de desplazamiento dadas las condiciones del entorno. En la ciudad de Monterrey es común que los nuevos fraccionamientos se localicen guardando una relativa cercanía con vialidades colectoras. De hecho, los fraccionamientos cerrados "dan su espalda" a calles colectoras que corren anónimamente entre los vallados. Las diferencias de velocidad de los transportes que por ahí circulan con respecto a la de los interiores de los fraccionamientos pueden ser enormes, de manera que se vuelve súmamente difícil para una persona vulnerable o discapacitada transitar por sus medios por estos lugares.

Paralelamente a esto, los proyectos de grandes equipamientos comerciales o de servicios se proyectan mayormente en los márgenes o en las cercanías de las vías colectoras principales, quizás por un criterio de concentración de funciones que poco a poco va eliminando la variedad y flexibilidad de los tejidos urbanos (de nuevo quizás por el apego a un imaginario dominante de lo que son "los buenos diseños").

Uno de los efectos inmediatos de ello es que una buena parte de las personas discapacitadas y vulnerables abandonan la intención de salir del restringido ámbito de sus barrios, quedando en condición de "reclusos" de su propio hogar. Un diseño urbano que incorpore la variedad a los conjuntos habitacionales debería seriamente de plantearse. Funciones de educación, de salud, de servicios públicos, de comercio, de ocio, etc., deberían formar parte del programa de los nuevos fraccionamientos, también planteándose un grado de flexibilidad en su diseño y funcionamiento, que permitiera la mudanza de servicios, toda vez que éstos ya no fueran necesarios (cambiar escuelas primarias por escuelas secundarias o por oficinas de gobierno, por ejemplo, cuando la población del sector ha envejecido o cambiado sustancialmente). Con lo que la incorporación de una capacidad de ser flexible de los diseños de los edificios no habitacionales, es fundamental para su concepción arquitectónica y eso también puede formar parte de los planes y reglamentos de edificación, tanto de cada fraccionamiento a través de su junta de vecinos, de mejoras, como de los propios municipios.

A través del análisis que realizamos, pudimos percatarnos de que los modelos de urbanización basados en viviendas unifamiliares resultan ser muy incómodos para realizar adecuaciones a las viviendas existentes. Una de las razones fundamentales de ello radica en la dimensión restringida de los terrenos.

Ciertamente, en términos de variación al tema inicial, un multifamiliar puede ser incluso menos flexible, cuando su diseño no permita la variación de modelos sobre una trama estructural base, pero cuando las viviendas unifamiliares se enfrentan a una transformación, la escases de terreno es aún más restrictiva, toda vez que las soluciones verticales son menos 
recomendables cuando el presupuesto es limitado para atender a usuarios discapacitados 0 vulnerables.

Por lo tanto, vale plantearse la necesidad de otros modelos de urbanización que por una parte permitan la adaptación de viviendas ante las variaciones de las necesidades de sus habitantes durante el ciclo de vida de las casas, por otra que ofrezcan la posibilidad de contar con acceso cercano a servicios urbanos, para en lo posible permitir una movilidad cómoda de los habitantes que les permita poder acercarse al ideal de contar con una variedad y riqueza vital. Y por otra parte, diseños urbanos que favorezcan el desarrollo de experiencias estéticas que fortalezcan y ayuden al desarrollo espiritual de los habitantes.

Esto es tanto más importante para personas con discapacidad o vulnerables, por el hecho de que la mayoría de los entornos urbanos de Monterrey presentan formidables obstáculos para su movilidad, lo que ha tenido el efecto de acrecentar su aislamiento, por lo que es importante el pensar para estas personas en la creación de entornos urbanos que ofrezcan oportunidades para el enriquecimiento espiritual de los habitantes a través del mismo diseño y la incorporación de experiencias artísticas de escala urbana.

Si la flexibilidad del diseño depende en una parte muy importante de la cantidad de terreno disponible para cada unidad, entonces es lógico pensar que si se reserva una cantidad razonable de terreno en cada unidad construida, esto será benéfico para conseguir futuras adaptaciones. Esto puede ser así para estos fines, pero, en la escala de la producción de un número importante de unidades, luego esto podría tener efectos perversos en cuanto a la cantidad de tierra a urbanizar, así como en los costos (económicos, ambientales, de transportes, etc.) de la urbanización, de la introducción de servicios, así como de los derivados de la movilidad, contribuyendo hacia una poco deseable dispersión urbana.

De todas maneras, de cara a las condiciones actuales de las viviendas sociales unifamiliares en la metrópoli, que carecen en algunos casos inclusive del terreno para un jardín, o de un patio que tenga las dimensiones suficientes para que jueguen los niños, sería necesario plantearse estudios serios sobre las necesidades reales de terreno para la edificación de las viviendas sociales.

\subsection{Una visión panorámica: la dimensión material del problema}

El diagnóstico que presenta el Programa Nacional de Viviendas 2014-2018 del Gobierno de México, reveló que existen en el país 28 millones 607 mil 568 viviendas. Un cálculo grueso realizado sobre la base de nuestra investigación de adaptación de las viviendas para la discapacidad reveló que al menos el $75.2 \%$ de las mismas no estarían pensadas, diseñadas, construidas o preparadas para alojar a pobladores discapacitados o que presenten algún grado de vulnerabilidad en este momento o en el futuro, lo que nos da un total de 21 millones, 512 mil 891 viviendas que posiblemente tendrían problemas de diseño en la actualidad. De acuerdo con este razonamiento, sería factible calcular los costos de adaptación de esas viviendas en la actualidad, para en un cierto sentido tener una manera de medir las dimensiones del problema y proyectar opciones viables de adaptación de las viviendas para que en el futuro puedan ofrecer mayor bienestar a sus moradores con independencia de su vulnerabilidad.

Para llevar a cabo este cálculo grueso, decidimos dividir las casas que podrían presentar problemas de adaptación en tres segmentos, que denominamos A, B y C, y que 
corresponderían aproximadamente con los segmentos que estudiamos. Es una forma muy especulativa de proceder, pero puede en principio funcionar para nuestro cálculo grueso si consideramos que estos tres modelos representan con mínimas variaciones a modelos similares por su área total construida y distribución; pero como probamos a través de nuestros experimentos, los costos de intervención de la vivienda que representa un segmento, es proporcionalmente hablando muy diferente al resto de los segmentos, no guardando en apariencia entre sí una razón o relación matemática evidente en cuanto al porcentaje de variación de la inversión necesaria para su puesta en óptimo funcionamiento.

Por lo que especulamos que los porcentajes de intervención y los costos, podríamos para este ejercicio, considerarlos como representativos de un segmento. Con estas consideraciones llegamos a elaborar la siguiente tabla.

Tabla 4. Costos de adaptación del parque habitacional mal acondicionado para su uso por la población de personas discapacitadas en México

\begin{tabular}{|c|c|c|c|c|c|c|}
\hline Segmento & $\begin{array}{l}\text { Costo } \\
\text { de } \\
\text { adaptaci } \\
\text { ón por } \\
\text { unidad } \\
\text { por } \\
\text { segmen } \\
\text { to }\end{array}$ & $\begin{array}{l}\text { Porcentaje } \\
\text { del total } \\
\text { del Parque } \\
\text { habitacion } \\
\text { al (2012) } \\
\text { por } \\
\text { segmento } \\
\text { de } \\
\text { viviendas } \\
\text { mal } \\
\text { adaptadas }\end{array}$ & $\begin{array}{l}\text { Total de } \\
\text { viviendas } \\
\text { por } \\
\text { segmento }\end{array}$ & $\begin{array}{l}\text { Valor de las } \\
\text { viviendas por } \\
\text { segmentos de las } \\
\text { viviendas mal } \\
\text { adaptadas }\end{array}$ & $\begin{array}{l}\text { Viviendas } \\
\text { ocupadas } \\
\text { por } \\
\text { personas } \\
\text { discapacita } \\
\text { das por } \\
\text { segmento }\end{array}$ & $\begin{array}{l}\text { Costo de la } \\
\text { adaptación del } \\
\text { parque de } \\
\text { viviendas por } \\
\text { segmento }\end{array}$ \\
\hline$A$ & 100,795 & $18.77 \%$ & $5,369,640$ & $1,487,390,280,000$ & 273,851 & $27,602,811,545$ \\
\hline B & 287,705 & $47.1 \%$ & $13,474,164$ & $7,410,790,200,000$ & 687,182 & $197,705,697,310$ \\
\hline $\mathrm{C}$ & 305,830 & $9.33 \%$ & $2,669,086$ & $3,587,251,584,000$ & 136,123 & $41,630,497,090$ \\
\hline Totales & & $75.2 \%$ & $21,512,890$ & $12,485,432,064,000$ & $1 ’ 097,156$ & $266,939,005,945$ \\
\hline
\end{tabular}

Fuente: Elaboración propia

A través de esta tabla pudimos estimar que el porcentaje promedio del costo sobre el valor total del parque de vivienda mal adaptada del país es de un $2.13 \%$. Puesto en perspectiva este valor resulta realista, ya que, según expertos en valuación inmobiliaria del país, este porcentaje ronda el criterio de "premio" o de "castigo" que se da en una valuación inmobiliaria a aquellas viviendas que exhiben un valor agregado (o una falta de aquel) como por ejemplo en su adaptación a las condiciones climatológicas locales. De acuerdo con el criterio en uso, se agregaría o se restaría al valor final de la tasación un 3\% cuando se cumpliera o se dejara de cumplir el criterio de construcción buscado (como el que hubiera un buen diseño bioclimático, por ejemplo).

El 2.3\%, reflejaría la cantidad de inversión necesaria para adaptar las viviendas para su uso por personas discapacitadas en relación al valor actual de las viviendas del país. Una medida que recomiendan los profesionales de la valuación inmobiliaria para que pueda darse un cambio es conducir ese costo a la vivienda que se adquirirá, de modo que cuando una persona se acerque con el promotor de viviendas y quiera adquirir una vivienda especialmente adaptada para personas con discapacidad, aporte un $2.3 \%$ más al costo total de la misma, tomando como precio base al de una casa no adaptada, y asimismo pueda obtener ese "premio" al valor de su vivienda cuando quiera vender su casa a un tercero.

Citación: NARVÁEZ TIJERINA, A. et al. Dimensiones de la adaptación de las viviendas para personas con discapacidad en México: tres estudios de caso. En: Libro de proceedings, CTV 2018. XII Congreso Internacional Ciudad y Territorio Virtual. "Ciudades y Territorios Inteligentes". UNCuyo, Mendoza, 5-7 septiembre 2018. Barcelona: CPSV, 2018, p. 193-226. 
Esta manera de financiar la adquisición de la casa bien adaptada, luego puede ser llevada hacia una fuente de aportación múltiple (sobre todo en los numerosos casos en los que un usuario con discapacidad cuente con recursos limitados para pagar ese sobreprecio), en la que podrían concurrir aportaciones provenientes de programas gubernamentales, de organizaciones no gubernamentales, de organizaciones filantrópicas, de la iniciativa privada, etc.

A pesar de lo enormes que pudieran verse los números gruesos expuestos en la Tabla 4, la proporción de la aportación puede resultar ser modesta considerando el valor de las viviendas construidas en el país.

Una medida adicional de ajuste, que ayudara a que se hicieran viviendas bien adaptadas para personas con discapacidad podría basarse en la solidaridad social, al distribuir el costo de la adaptación de las viviendas para personas con discapacidad de un fraccionamiento entre todos los habitantes, buscando que un segmento de este costo también fuera absorbido por el desarrollador inmobiliario.

El gobierno municipal podría responder a esta clase de iniciativas considerando rebajas en el impuesto predial de todo el fraccionamiento, mientras que otros niveles de gobierno podrían auxiliarse de programas especiales de financiamiento que se reflejaran en la disminución de costos de servicios públicos para los moradores o en exenciones de impuestos temporales o a través de devoluciones sobre las declaraciones anuales de impuestos de los moradores de dichos fraccionamientos solidarios. De tal forma que se produjera una cadena de solidaridad entre diversos actores involucrados en la producción habitacional.

Estas maneras de incluir en los actuales proyectos de vivienda social a la necesidad de que un segmento de las viviendas que se construyen se hagan considerando una normativa de edificación y diseño diferente que haga posible el que sean habitadas por personas con diversas discapacidades, no excluyen otras formas de asociación para la producción, quizás más imaginativas, que no han sido expuestas previamente en este capítulo. Pero lo que es necesario resaltar es que el conseguir esta clase de concurrencia solidaria de los diversos actores (habitantes, desarrolladores, gobiernos, asociaciones no gubernamentales, etc.) es realmente difícil en el contexto cultural actual de las grandes ciudades de México. ¿Por qué?

\subsection{Una mirada al problema desde los imaginarios urbanos}

La producción de la vivienda social en las grandes ciudades mexicanas en la actualidad se basa principalmente en concebirla como un producto de uso exclusivo por el comprador. En una relación de mercado concebida de esa manera, la vivienda pasa a ser un producto que se adquiere en una transacción más o menos cerrada entre una parte vendedora y una parte compradora. Independientemente de que exista una gran cadena de personas en el proceso de construcción de la vivienda desde que es un puro terreno en breña, hasta que es adquirida por el usuario final, normalmente cada etapa de esa producción quedará "sellada" para la posteridad mediante una transacción comercial entre el productor de la vivienda (normalmente un desarrollador inmobiliario) y todos los actores involucrados en cada etapa de su construcción.

Que en medio de dicho proceso surjan problemas relacionados con la justicia de las retribuciones erogadas por el desarrollador en cada etapa, es independiente del hecho de que

Citación: NARVÁEZ TIJERINA, A. et al. Dimensiones de la adaptación de las viviendas para personas con discapacidad en México: tres estudios de caso. En: Libro de proceedings, CTV 2018. XII Congreso Internacional Ciudad y Territorio Virtual. "Ciudades y Territorios Inteligentes". UNCuyo, Mendoza, 5-7 septiembre 2018. Barcelona: CPSV, 2018, p. 193-226. 
en cada etapa de la producción sólo se considera que la tierra, los bienes y los servicios que fueron puestos en juego para la producción de la vivienda, representan retribución monetaria y ninguna otra cosa más, con lo que es natural luego que el desarrollador considere que lo que tiene como bien final -la vivienda- es una mercancía cuyo valor más importante es el monetario.

Aunque la propaganda de las desarrolladoras pueda hablarnos de la integración de las familias, del respeto al medio ambiente y una serie de valores sociales muy apreciados en nuestros días, la verdad desnuda es que al final, el desarrollador va a basar sus cálculos para la elaboración de proyectos y la producción material de las viviendas sociales en el balance contable, eso sin duda porque la vivienda es eso en su concepción.

El comprador es mucho más complejo de reducir. Hay una variación grandísima en lo que podría representar la casa para el comprador, es un patrimonio, indudablemente, pero también es el eje del cariño, el centro del que surgen todos los viajes (conscientes y oníricos), el origen de la luz y de las sombras de la vida, el escenario de todos los amores y de la añoranza, el sitio de la muerte y del duelo, del nacimiento y del paso por las etapas de la vida.

Es la casa un universo total, sí, con todos los matices que podamos imaginar y aun los que no podamos. Pero cuando la casa es adquirida: un proyecto que madura cuando se tiene un ingreso que lo sostenga, la visita a unos señores en un fraccionamiento que muestran las casas y hacen imaginar un idilio lleno de esperanza, la búsqueda de alguien que otorgue un crédito (el patrón, el gobierno, el banco), la transacción, la visita al notario para que formalice la propiedad, las amenazas veladas en documentos que rara vez se leen y que nos hacen dueños y al mismo tiempo tributadores -esclavos- de otros; la entrega, el contratar los servicios, el ir comprando los muebles y planeando las adaptaciones... cuando la casa es adquirida así, se entra al juego de mercado, a las reglas con las que ha trabajado desde antes el desarrollador. El comprador asume de esta forma unos valores que están subsumidos bajo el ritual de adquirir una vivienda, como los valores que la representan.

No hay mejor forma de involucrar a una persona en una manera de concebir al mundo que a través de hacerle participar -por interés propio, por supuesto- en un ritual realizado con el fin de instituir una concepción de mundo tenida como cierta. La producción y adquisición de la casa, de este modo, repetida constantemente y en grandes cantidades, podemos concebirla como ese ritual que nos hace comulgar en el imaginario social que sobrepone el valor mercantil de la vivienda por encima de otros valores que le son inherentes en nuestra cultura. Diremos además que de este modo subordina todos aquellos valores no mercantiles a la concepción de la vivienda como un bien de consumo.

Esta manera de concebir a la vivienda, luego se mete hasta la concepción de lo que es la casa -nuestra casa- y ésta se convierte en un objeto comercializable, en uno más de los bienes que ayudan a "armar" a la vivienda, conectándose de esta manera a un modo de vida consumista. Es posible afirmar que esta es una de las vías a través de las cuales en la construcción de la casa queda excluido el papel que ésta juega para ir formando a la sociedad.

La solidaridad es concebible como un valor fundamental en la construcción social, pero al mercantilizarse así el proceso de habitar una vivienda, es posible que se limite la solidaridad social, cuando menos en el ámbito que compete a proyectar, construir, y adquirir una vivienda para ser habitada. Eliminada la solidaridad social en este proceso, es explicable por qué la

Citación: NARVÁEZ TIJERINA, A. et al. Dimensiones de la adaptación de las viviendas para personas con discapacidad en México: tres estudios de caso. En: Libro de proceedings, CTV 2018. XII Congreso Internacional Ciudad y Territorio Virtual. "Ciudades y Territorios Inteligentes". UNCuyo, Mendoza, 5-7 septiembre 2018. Barcelona: CPSV, 2018, p. 193-226. 
reticencia a asumir costos compartidos en la producción de viviendas especialmente adaptadas para su uso por personas vulnerables, por parte de los actores involucrados en su construcción.

Existen experiencias de gran solidaridad social para la construcción de las viviendas en comunidades tradicionales de México, que revelan hasta qué punto una forma diferente de concebir un proceso de construcción, puede tener repercusiones en la integración social.

El tequio, (Zolla, Zolla Márquez, 2004) un sistema de construcción solidario de raíz prehispánica, ha quedado como uso y costumbre de algunos municipios de Oaxaca, y está de tal forma arraigado, que ha sido considerado en la Constitución Política de ese estado mexicano como expresión de la solidaridad comunitaria, llegándose a considerar el trabajo realizado así en algunos casos, como el pago de las contribuciones municipales por parte de los participantes.

Un exalumno oaxaqueño, proveniente de la región mixe, fue el primero en hablarme del tequio, hace ya más de 20 años; desde entonces he estado muy interesado en esta forma de asociación solidaria. Él me refirió que, en su pueblo, cuando alguien se casa, la comunidad le ayuda a edificar su morada, luego ello generará una obligación para que esa persona que ha recibido el beneficio del Tequio otorgue su trabajo a la comunidad cuando se requiera. Luego me explicó que el tequio se aplica no sólo a viviendas, sino a la construcción de obras de uso comunitario, como infraestructuras o edificios públicos.

Estas otras maneras de concebir la construcción, estos que hemos llamado antes rituales, atraen otros valores que parecen posarse sobre las viviendas nuestras. Se forman imaginarios que se basan en otra estructura de valores para asignar los significados a las cosas y a las personas. Sería interesante partir de estas raíces -de las acciones de construir, del hacer- para transformar a los objetos que habitamos y con los que vivimos.

La solidaridad social parece ser la antítesis del egoísmo generalizado que impide que persigamos unos fines comunes que impliquen la aportación de recursos propios sin un beneficio individual o de la organización de uno, que sea aparente e inmediato.

El egoísmo es otro aspecto que, de la mano de la mercantilización, puede ayudarnos a explicar por qué se vuelve tan difícil plantear rutas alternativas para la construcción de viviendas bien adaptadas.

Es necesario entonces plantear como corolario de estas reflexiones que es indispensable trabajar sobre los imaginarios sociales de la discapacidad, para a partir de ello poder incidir en la opinión ciudadana, informándole sobre el peligro de la inacción y sobre la necesidad de la colaboración para alcanzar un bienestar pleno, evitando con ello la polarización.

\section{Bibliografía}

BENTLEY, I. et al. Entornos vitales. Hacia un diseño urbano y arquitectónico más humano, Barcelona, Editorial Gustavo Gili, 1999. 151 p.

Citación: NARVÁEZ TIJERINA, A. et al. Dimensiones de la adaptación de las viviendas para personas con discapacidad en México: tres estudios de caso. En: Libro de proceedings, CTV 2018. XII Congreso Internacional Ciudad y Territorio Virtual. "Ciudades y Territorios Inteligentes". UNCuyo, Mendoza, 5-7 septiembre 2018. Barcelona: CPSV, 2018, p. 193-226. 
CÓRDOBA-ANDRADE, L.; GÓMEZ-BENITO, J. y VERDUGO-ALONSO, M. Á. Calidad de vida familiar en personas con discapacidad: un análisis comparativo. En: Universitas Psychologica, 7, 2, pp. 369-383. 2008.

DIARIO OFICIAL DE LA FEDERACIÓN. Norma Oficial Mexicana NOM-233-SSA1-2003, que establece los requisitos arquitectónicos para facilitar el acceso, tránsito, uso y permanencia de las personas con discapacidad en establecimientos de atención médica ambulatoria y hospitalaria del Sistema Nacional de Salud. 15-09-2004. DIARIO OFICIAL DE LA FEDERACIÓN, p. 1.

DÍAZ, J. E. y MALPICA, C. R. Representaciones sociales de la discapacidad. En: Investigación en Salud, 8, 3, pp. 158-164. 2006.

FITCH, J. y MORILLON, D. El confort térmico como variable adicional al método tradicional de valuación de inmuebles: Caso vivienda del Área Metropolitana de Monterrey, México. En: ASADES, Avances en Energía Renovables y Medio Ambiente, 5, pp. 01.87-01.91, 2001. Mendoza Argentina, Buenos Aires, INENCO.

HARTLEY, S. y MOHAMMAD, M. Using qualitative research methods for disability research in majority world countries. En: Asia Pacific Disability Rehabilitation Journal, 14, 2, pp. 103-112. 2003.

HOREJES, T. The (Mis)interpretation of Disability: Why Quantitative Research May be Ineffective in American Politics. En: International Congress of Qualitative Inquiry, UrbanaChampaign, University of Illinois. 2007.

IMSS. Elementos de apoyo para el discapacitado físico: invidentes y silentes. Instituto Mexicano del Seguro Social, México, 1993. 155 p.

MAYCOTTE PANSZA, E. Espacios abiertos y calidad de vida en conjuntos habitacionales organizados en condominio. El caso de la vivienda tipo económica en Ciudad Juárez, Chihuahua. Tesis doctoral inédita. Colima, Universidad de Colima, 2007.

NARVÁEZ, A. Etnografía para la investigación en arquitectura y urbanismo. Monterrey, UANL, 2011.

NARVÁEZ, A. y SOTO, K. Imaginarios urbanos de la discapacidad y la exclusión. En: ACE: Architecture, City and Environment, Arquitectura, Ciudad y Entorno, 8 (24): 11-37. Febrero de 2014. [Fecha consulta: 21/01/2016] Disponible en: http://hdl.handle.net/2099/14319 DOI: http://dx.doi.org/10.5821/ace.8.24.2754

OMS. Organización Mundial de la Salud. CIF. Clasificación Internacional del Funcionamiento, de la discapacidad y de la salud. España, OMS, OPS, Imserso, 2001.

PANERO, J. y ZELNIK, M. Las Dimensiones Humanas en los Espacios Interiores Estándares Antropométricos. México, Ediciones G. Gili, 1984. 320 p.

Citación: NARVÁEZ TIJERINA, A. et al. Dimensiones de la adaptación de las viviendas para personas con discapacidad en México: tres estudios de caso. En: Libro de proceedings, CTV 2018. XII Congreso Internacional Ciudad y Territorio Virtual. "Ciudades y Territorios Inteligentes". UNCuyo, Mendoza, 5-7 septiembre 2018. Barcelona: CPSV, 2018, p. 193-226. 
QUINN, G. y DEGENER, Th. Derechos humanos y discapacidad. Uso actual y posibilidades futuras de los instrumentos de derechos humanos de las Naciones Unidas en el contexto de la discapacidad. Ginebra-Nueva York, ONU, 2002.

SECRETARÍA DE GOBERNACIÓN. Programa Nacional de Vivienda 2014-2018. Disponible en: http://www.dof.gob.mx/nota detalle.php?codigo $=5342865 \&$ fecha $=30 / 04 / 2014$ [Fecha consulta: 21/01/2016]

SIN AUTOR. Se enfocará INFONAVIT a sectores de menos ingresos. En: Diario de Ciudad Juárez, Ciudad Juárez, Chihuahua, México. 03-10-2006. p. 1.

TOBOSO-MARTíN, M. y ROGERO-GARCÍA, J. Diseño para todos en la investigación social sobre personas con discapacidad. En: Revista Española de Investigaciones Sociológicas, 140, pp. 163-172. 2012.

WAKEFIELD, D. Architectural and Transportation Barriers Compliance Board. En: Federal Register, 65, 246, pp. 80500-80528. 21 de diciembre de 2000.

ZOLLA, C. y ZOLLA MÁRQUEZ, E. Los pueblos indígenas de México. 100 preguntas. México, Universidad Nacional Autónoma de México, 2004. 392 p.

\section{Sitios Web}

http://cuentame.inegi.org.mx/poblacion/discapacidad.aspx?tema=P

[Fecha de consulta: 22/12/2014]

http://www.nuevoamanecer.edu.mx/paralisis/indicadores impacto.asp

[Fecha de consulta: 22/12/2014]

http://monterrey.ruba.com.mx

[Fecha de consulta: 22/12/2014]

http://www.javer.com.mx/fraccionamientos/Privadas-Cumbres-Diamante.html

[Fecha de consulta: 22/12/2014]

Citación: NARVÁEZ TIJERINA, A. et al. Dimensiones de la adaptación de las viviendas para personas con discapacidad en México: tres estudios de caso. En: Libro de proceedings, CTV 2018. XII Congreso Internacional Ciudad y Territorio Virtual. "Ciudades y Territorios Inteligentes". UNCuyo, Mendoza, 5-7 septiembre 2018. Barcelona: CPSV, 2018, p. 193-226. 